OPEN ACCESS

Edited by:

Li-Fan Lu,

University of California, San Diego,

United States

Reviewed by:

Ye Zheng,

Salk Institute for Biological Studies,

United States

Yongqiang Feng,

St. Jude Children's Research Hospital,

United States

*Correspondence:

Fan Pan

fan.pan@siat.ac.cn

Specialty section:

This article was submitted to

Immunological Tolerance

and Regulation,

a section of the journal

Frontiers in Immunology

Received: 05 November 2020

Accepted: 17 March 2021

Published: 12 April 2021

Citation:

Dong Y, Yang C and Pan F (2021)

Post-Translational Regulations of

Foxp3 in Treg Cells and Their

Therapeutic Applications.

Front. Immunol. 12:626172.

doi: 10.3389/fimmu.2021.626172

\section{Post-Translational Regulations of Foxp3 in Treg Cells and Their Therapeutic Applications}

\author{
Yi Dong ${ }^{1}$, Cuiping Yang ${ }^{2}$ and Fan Pan ${ }^{3 *}$ \\ ${ }^{1}$ Department of Cell Biology, Johns Hopkins University School of Medicine, Baltimore, MD, United States, ${ }^{2}$ Department of \\ Gastroenterology, Ruijin Hospital, Shanghai Jiaotong University School of Medicine, Shanghai, China, ${ }^{3}$ Institute of Biomedicine and \\ Biotechnology, Shenzhen Institute of Advanced Technology, Chinese Academy of Science, Shenzhen, China
}

Regulatory $\mathrm{T}$ (Treg) cells are indispensable for immune homeostasis due to their roles in peripheral tolerance. As the master transcription factor of Treg cells, Forkhead box P3 (Foxp3) strongly regulates Treg function and plasticity. Because of this, considerable research efforts have been directed at elucidating the mechanisms controlling Foxp3 and its co-regulators. Such work is not only advancing our understanding on Treg cell biology, but also uncovering novel targets for clinical manipulation in autoimmune diseases, organ transplantation, and tumor therapies. Recently, many studies have explored the posttranslational regulation of Foxp3, which have shown that acetylation, phosphorylation, glycosylation, methylation, and ubiquitination are important for determining Foxp3 function and plasticity. Additionally, some of these targets have been implicated to have great therapeutic values. In this review, we will discuss emerging evidence of posttranslational regulations on Foxp3 in Treg cells and their exciting therapeutic applications.

Keywords: regulatory $\mathrm{T}$ cells, Foxp3, post-translational regulation, ubiquitination, glycosylation, acetylation, phosphorylation, therapeutic application

\section{INTRODUCTION}

Thanks to the precious gift inherited from jawed fish ancestors thought to have lived some 500 million years ago, our immune defenses are equipped with a powerful adaptive arm with the ability to mount responses to a near-infinite diversity of targets (1). However, these immune responses can sometimes be overpowered or misdirected to target self-targets. Fortunately, complex mechanisms of immune tolerance have co-evolved to ensure proper regulations on both adaptive and innate immune systems - an immune homeostasis state in the absence of an imminent threat. While central tolerance prevents the development of self-reactive $\mathrm{T}$ lymphocytes during their maturation in the thymus, mechanisms of peripheral tolerance suppress the activation of rogue $\mathrm{T}$ cells that escape this safeguard (2). Among these, regulatory $\mathrm{T}$ (Treg) cells play essential roles in maintaining immune homeostasis by moderating the intensity of immune responses and suppressing the activation of self-reactive leukocytes (3). 
The concept of a regulatory $\mathrm{T}$ cell lineage has its roots in the "suppressor T cells". Back in 1969 and 1970, Nishizuka and Gershon found that certain subsets of $\mathrm{T}$ cells from the thymus had the ability to suppress the activity of other immune cells $(4,5)$. Later, in 1995, Sakaguchi identified CD25 (IL-2 receptor $\alpha$ chain) as a reliable marker for these $\mathrm{CD} 4^{+}$suppressive T cells (6). This minor $\mathrm{T}$ cell population constitutes $5-10 \%$ of the peripheral $\mathrm{CD}^{+} \mathrm{T}$ cell pool in normal naïve adult mice (i.e., those kept in specific pathogen free (SPF) condition without pathogen challenge), and loss of these cells led to severe autoimmune diseases (7). In 2001, the mutation of a gene encoding the transcription factor Forkhead box P3 (Foxp3) was identified as the disease-causative event underlying IPEX (Immune dysregulation, Polyendocrinopathy, Enteropathy, Xlinked syndrome) syndrome in humans and the Scurfy phenotype in mice (8-10). Immediately after the discovery of Foxp3, in 2003, Sakaguchi, Rudensky, and Ramsdell confirmed that Foxp3 is the master transcription factor that programs the development and function of regulatory T cells (11-13). Since then, intensive research has been focused on Treg cells to elucidate their roles in different tissues and under a variety of physiological and pathological conditions. It is now well-appreciated that Treg cells play conserved functions in tissue pathophysiology and metabolism across vertebrate species. In addition to their more classical role in immune suppression, these cells are shown to participate in wound healing, tissue homeostasis, and regeneration (14-16). More detailed reviews in this perspective can be found elsewhere (17-19).

After decades of studies, we now understand that these Foxp $3^{+}$ Treg cells use multiple different mechanisms to suppress immune activation. These include mechanisms acting through direct cell-cell interactions. For example, Treg cells express coinhibitory molecules like LAG3, CTLA-4, GITR, and PD-1 to inhibit DC maturation (2023) and effector T cell function (24). Paracrine release of suppressive mediators is another avenue for suppression. Treg cells are known to produce anti-inflammatory cytokines like TGF- $\beta$, IL-10, and IL-35 to inhibit effector $\mathrm{T}$ cells. Indirect means have also been studied, and Treg cells are known to sequester the growth factor IL-2 from other leukocytes, thus disrupting their survival and function (25). Losing or disrupting Foxp3 undercuts these diverse mechanisms of immune suppression significantly, which leads to a loss of immune control and severe autoimmune diseases (25).

So far, multiple layers of regulations have been identified to control the function and the turnover of Foxp3, especially transcriptional and post-translational regulations $(26,27)$. Among these, post-translational regulation is of high interest due to its versatility and specificity. This is because each of these modifications is orchestrated by a highly specific set of proteins with a variety of functions. For example, ubiquitin-dependent modification involves many unique E3 ligases for either polyubiquitination-dependent proteasome degradation or monoubiquitinated modification for signaling cascades (28). Due to these features, post-translational regulation provides new insights into protein functions and therapeutic targets (29).

Since the post-translational regulation of Foxp3 has become, of late, an expansive topic, in this review, we will focus on a selective number of modifications, including phosphorylation, dephosphorylation, acetylation, deacetylation, methylation, glycosylation, ubiquitination, deubiquitination, and others. Among these modifications, we will put additional emphasis on ubiquitination and deubiquitination, and discuss some recent therapeutic applications of Treg cells to build a connection between basic research and clinical transformation.

\section{CLASSIFICATION OF TREG}

After decades of studies, we now understand that Foxp ${ }^{+}$Treg cells are composed of a heterogeneous pool of cells arising from distinct tissues of origin (30). Treg subsets have been characterized with different potentials for proliferation and suppression due to the interplay of both intrinsic and extrinsic mediators (31). Accordingly, many different criteria have been suggested to stratify and classify Tregs. Here, we will only cover some of the most general approaches.

Based on their origin, Tregs can be classified as those having developed in the thymus or those induced in peripheral tissues. The former is normally called natural Treg (nTreg) or thymic Treg (tTreg) and the latter is known as peripheral Treg (pTreg) or inducible Treg (iTreg), especially when generated in vitro. nTreg cells are developed from $\mathrm{CD} 4^{+} \mathrm{CD}^{-}$single positive $\mathrm{T}$ cells in the thymus, and iTreg cells are derived from non-Treg precursors (i.e., naïve CD4+ T cells or $\mathrm{CD}^{+} \mathrm{T}$ conv cells) (32). While both nTreg and iTreg require IL-2 to maintain cell survival and suppressive function (33-36), TGF- $\beta$ is critical for iTreg induction $(32,37)$. Additionally, IL-35, retinoic acid, strong TCR activation (signal 1) with weak co-stimulation (signal 2), and commensal microbiota may also be important for iTreg induction and development (3846). Last but not least, the TCRs of nTregs are thought to generally recognize self-antigens $(47,48)$, while iTregs tend to express TCR targeting foreign antigens (49-51). Despite some controversies (5258), a common approach to distinguish tTreg and pTreg is based on transcription factor Helios and cell surface glycoprotein neuropilin1 (NRP-1), which are highly expressed on nTreg cells $(59,60)$.

Treg cells can also be classified by different means, including functional and phenotypic distinctions (61). For example, in terms of suppressive function and proliferation potential, human Treg cells can be classified as CD45RA ${ }^{+}$Foxp $3^{\text {int }}$ resting Treg (rTreg) or CD45RA Foxp ${ }^{\text {high }}$ effector Treg (eTreg) cells. Although both rTreg and eTreg are immunosuppressive in vitro, rTreg cells have a lower suppressive activity than eTreg cells. However, rTreg cells can be activated to proliferate and differentiate into eTreg cells, but eTreg cells have been described as anergic and prone to apoptosis (31). Furthermore, reflecting distinct activation states, Tregs can be classified as Foxp $3^{\text {pos }}$ Helios $^{\text {neg }}$ or Foxp $3^{\text {pos }}$ Helios $^{\text {pos }}$ Treg cells. The latter represents recently activated Tregs as they express higher Foxp3 and significantly more Ki67 (62). Overall, Treg cells are highly heterogenous and proper criteria are needed to further elucidate their differences.

\section{FOXP3 STRUCTURE AND ITS CO-REGULATORS}

Foxp3 belongs to the forkhead box (Fox) family, subfamily P. In mammals, there are four members in this subfamily, namely 
Foxp1-4 (63). Among these, FOXP3 is well conserved among mammals. For example, human and mouse FOXP3 share 91\% similarity in amino acid sequences (64). In human, FOXP3 gene locates on the short arm of Chromosome X (Xp11.23). It is about 20,039 bp long including 11 coding exons and one non-coding exon (exon 1) (10). In terms of Foxp3 transcription, four alternatively spliced isoforms have been identified, including full-length Foxp3 (1,869 bp), Foxp3 $\triangle 2$, Foxp3 $\triangle 7$, and Foxp3 $\triangle 2 \triangle 7$. Among these, $70 \%$ of Foxp3 mRNAs are Foxp3 $\triangle 2$, which lack retinoic acid-related orphan receptor $\gamma t$ (ROR $\gamma \mathrm{t}$ ) interaction domain (65). Besides, both full-length Foxp3 and Foxp $3 \triangle 2$ produce Foxp3 protein with normal functions (66).

Foxp3 protein is about 431 amino acids long and $47.24 \mathrm{kDa}$ in molecular weight. It includes four functional domains, namely the repressor (aa 1-190), zinc finger (ZF, aa 197-222), leucine zipper (LZ, aa 239-260), and Fork-head domain (FHD, aa 337-423) (67) (Figure 1A). In brief, the repressor domain is located at the $\mathrm{N}$-terminal region and is required to suppress NFAT-mediated transcriptional signaling, for example, suppressing IL-2 production (68). The zinc finger domain is necessary and sufficient for Foxp3 homodimerization and heterodimerization with Foxp1 (69), thus regulating its transcriptional regulatory functions (70). Similarly, the leucine zipper domain also mediates Foxp3 oligomerization by forming a dynamic two-strand anti-parallel $\alpha$-helical coiled-coil structure (70). Finally, the Forkhead domain is important for DNA binding and nuclear import (71). It recognizes a core $7 \mathrm{bp}$ DNA-binding sequence 5'-RWAAAYA-3' $(\mathrm{R}=\mathrm{A} / \mathrm{G}$; $\mathrm{W}=\mathrm{T} / \mathrm{A}$; $\mathrm{Y}=\mathrm{C} / \mathrm{T})(72-74)$.

As the master transcription factor of Treg cells, Foxp3 can form large protein complexes with other co-factors. These complexes vary from 300 to $1,200 \mathrm{kDa}$ in size and may involve up to 361 different potential partners $(75,76)$. Some of the characterized co-factors are: NFAT (77), RUNX1 (78), ROR $\alpha$ (79), Rel A and c-Rel (80), IRF4 (81), Eos (82), STAT3 (83), HIF1 $\alpha$ (84), GATA-3 (75), KAP1 (85), EZH2 (86), and Helios (87) (Figure 1B). Besides, these co-factors can further bind with other factors to form distinct functional complexes, including transcriptional activation/repression, ubiquitination, acetylation, etc. (76).

\section{REGULATION OF FOXP3}

Foxp3 is tightly regulated by a network of different mechanisms with certain redundancy. Epigenetically, Foxp 3 can be regulated DNA methylation, histone modification, and nucleosome positioning (88). For example, Foxp3 expression can be regulated by the conserved non-coding sequences 2 (CNS 2) within the Foxp3 locus through DNA methylation (89). Transcriptionally, USP22 leads to H2BK120Ub on chromatins among the FOXP3 locus to enhance its transcription (90). As for post-transcriptional modifications, many factors play important roles in regulating the conversion of precursor Foxp3 messenger RNA transcripts into mature messenger RNA. For example,
microRNAs (miRNAs) including miR-24, miR-31, and miR210 can lead to Foxp3 mRNA degradation, which prevents Foxp3 translation $(91,92)$. In this review, we will briefly cover transcriptional regulation of Foxp3 and specifically discuss posttranslational regulation of Foxp3.

\section{Modification of Foxp3 Expression at Transcriptional Level}

Foxp3 can be regulated by a number of cis-acting elements, which are located on the promoter and the enhancer regions (CNS0, CNS1, CNS2, and CNS3) of the Foxp3 locus $(93,94)$. These regions contain binding sequences for transcription factors that are induced by extracellular signaling, including TCR, CD28, TGF- $\beta R$, and IL-2R signaling (89). In this section, we will review four major pathways that regulate Foxp3 at the transcriptional level.

Upon T cell stimulation, TCR-induced NF- $\kappa B$ pathway plays an important role in regulating Foxp3 expression and Treg development. Mutating or deleting many key enzymes within the pathway, including PKC- $\theta$ (95), Bcl-10 (96), CARMA-1 (97, 98), IKK2 (99), and c-Rel (100-102), have been shown to reduce Foxp3 expression and Treg frequency significantly. Further studies have shown that $\mathrm{c}-\mathrm{Rel}$ is the key NF- $\mathrm{KB}$ subunit that binds to the promoter, CNS2, and CNS3 to regulate Foxp3 transcription $(93,103)$.

Another important pathway is the PLC $\gamma$-NFAT/AP-1 pathway. Upon TCR engagement, PLC $\gamma$ induces calcium influx, which leads to the activation of NFAT1 (104). NFAT1 not only plays an important role in maintaining Foxp3 expression (105), but also acts collaboratively with Foxp3 to regulate IL-2, CTLA-4, and CD25 (77). Besides, PLC $\gamma$ induces the activation of FOS/JUN, which leads to the activation of the AP1-NFAT transcriptional complex (106). In the Foxp3 locus, three NFAT and three AP1 binding sites are situated in close proximity to each other, which further supports their collective role in regulating Foxp3 expression (107).

Besides T cell stimulation, IL-2 signaling is also important for Treg survival and function. It has been shown that IL-2 receptor subunits IL-2R $\beta$ (CD122) and IL-2R $\gamma(\mathrm{CD} 132)$ are essential for Foxp3 expression, as losing them leads to no detectable Foxp $3^{+} \mathrm{T}$ cells in mice (108-110). Additionally, losing IL-2Ra would impair the development of Treg cells in the thymus and reduce the suppressive function in the peripheral $(111,112)$. In brief, upon IL-2 binding, the IL-2 receptor triggers JAK1 and JAK3 phosphorylation, which leads to the activation of STAT3 and STAT5 (113). Then, dimerized STAT5 will bind to the promoter and enhancer in CNS2 region, supporting the transcription of Foxp3 $(110,114)$. This signaling pathway is important for Treg development in the thymus $(110,114)$. It also plays a major role in the homeostasis and function of Treg cells in the peripheral $(115,116)$.

TGF- $\beta$ is an important cytokine for both Treg induction and maintenance (33). Recent studies have explained the role of this TGF- $\beta$-Smad signaling in regulating Foxp3 expression. Both Smad2 and Smad3 are redundantly essential in regulating Foxp3 expression, demonstrated by double knockout mouse 
A

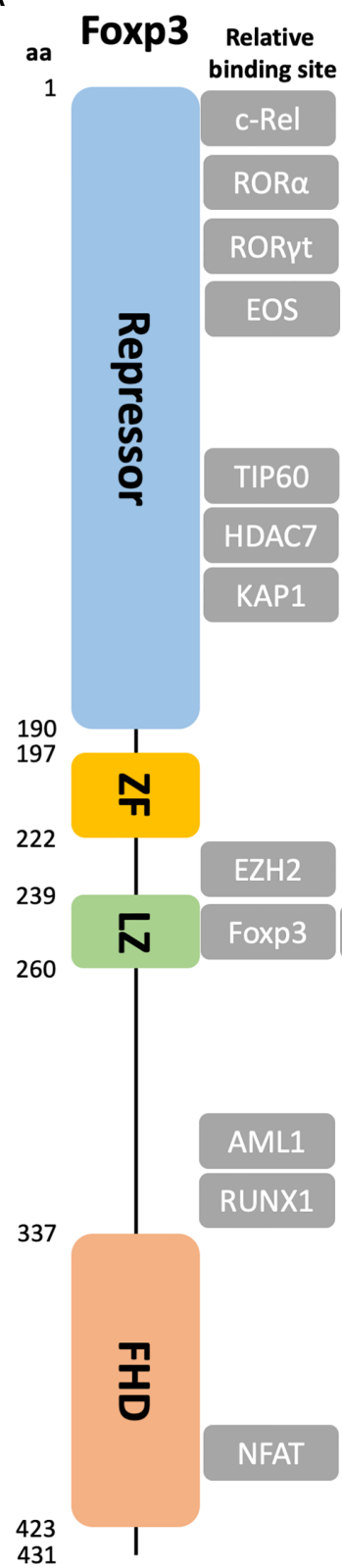

\begin{tabular}{|c|}
$\begin{array}{c}\text { Unknown } \\
\text { binding site }\end{array}$ \\
\hline Rel A \\
\hline IRF4 \\
\hline STAT3 \\
\hline GATA-3 \\
\hline Helios \\
\hline HIF1 $\alpha$ \\
\hline
\end{tabular}

C

\begin{tabular}{|c|c|c|c|c|c|}
\hline Domain & Location & Species & Type of PTM & Modifier & Function \\
\hline \multirow{18}{*}{ Repressor } & Ser-19 & Mouse & Phosphorylation & CDK2 & Negative \\
\hline & Ser-19 & Human & Phosphorylation & NLK & Positive \\
\hline & Arg-27 & Human & Methylation & PRMT5 & Positive \\
\hline & Lys-31 & Human & Acetylation & p300 & Positive \\
\hline & Lys-31 & Human & Ubiquitination & RNF31 & Positive \\
\hline & Ser-33 & Mouse & Phosphorylation & PIM2 & Negative \\
\hline & Thr-38 & Mouse & O-GlcNAc & OGT/OGA & Positive \\
\hline & Ser-41 & Mouse & Phosphorylation & PIM2 & Negative \\
\hline & Arg-48 & Human & Methylation & PRMT1 & Positive \\
\hline & Arg-51 & Human & Methylation & PRMT1 & Positive \\
\hline & Arg-51 & Human & Methylation & PRMT5 & Positive \\
\hline & Ser-57 & Mouse & O-GlcNAc & OGT/OGA & Positive \\
\hline & Ser-58 & Mouse & O-GlcNAc & OGT/OGA & Positive \\
\hline & Arg-146 & Human & Methylation & PRMT5 & Positive \\
\hline & Ser-156 & Human & Phosphorylation & NLK & Positive \\
\hline & Thr-175 & Mouse & Phosphorylation & CDK2 & Negative \\
\hline & Lys-179 & Human & Acetylation & TIP60/p300 & Positive \\
\hline & Ser-189 & Human & Phosphorylation & NLK & Positive \\
\hline \multirow{3}{*}{$\mathrm{ZF}$} & Lys-200 & Human & Ubiquitination & RNF31 & Positive \\
\hline & Lys-206 & Human & Deubiquitination & USP21 & Positive \\
\hline & Lys-216 & Human & Deubiquitination & USP21 & Positive \\
\hline \multirow{10}{*}{ LZ } & Lys-227 & Human & Acetylation & TIP60/p300 & Positive \\
\hline & Lys-227 & Human & Ubiquitination & Stub1 & Negative \\
\hline & Lys-227 & Human & Deubiquitination & USP21 & Positive \\
\hline & Lys-249 & Mouse & Deubiquitination & USP7 & Positive \\
\hline & Lys-250 & Human & Acetylation & p300 & Negative \\
\hline & Lys-250 & Human & Ubiquitination & RNF31 & Positive \\
\hline & Lys-250 & Human & Ubiquitination & Stubl & Negative \\
\hline & Lys-251 & Mouse & Deubiquitination & USP7 & Positive \\
\hline & Lys-252 & Human & Acetylation & p300 & Negative \\
\hline & Lys-252 & Human & Deubiquitination & USP21 & Positive \\
\hline & Lys-262 & Mouse & Acetylation & p300 & Positive \\
\hline & Lys-262 & Mouse & Ubiquitination & TRAF6 & Positive \\
\hline & Lys-263 & Human & Ubiquitination & RNF31 & Positive \\
\hline & Lys-263 & Human & Ubiquitination & Stub1 & Negative \\
\hline & Lys-263 & Mouse & Deubiquitination & USP7 & Positive \\
\hline & Lys-267 & Mouse & Acetylation & p300 & Positive \\
\hline & Lys-267 & Mouse & Deubiquitination & USP7 & Positive \\
\hline & Lys-268 & Human & Ubiquitination & RNF31 & Positive \\
\hline & Lys-268 & Human & Ubiquitination & Stub1 & Negative \\
\hline & Ser-270 & Mouse & O-GlcNAc & OGT/OGA & Positive \\
\hline & Ser-273 & Human & Phosphorylation & NLK & Positive \\
\hline & Ser-273 & Mouse & O-GlcNAc & OGT/OGA & Positive \\
\hline & Lys-277 & Human & Deubiquitination & USP21 & Positive \\
\hline & Ser-278 & Human & Phosphorylation & NLK & Positive \\
\hline & Ser-295 & Human & Phosphorylation & NLK & Positive \\
\hline & Lys-332 & Human & Deubiquitination & USP21 & Positive \\
\hline \multirow{10}{*}{ FHD } & Thr-341 & Human & Phosphorylation & NLK & Positive \\
\hline & Lys-382 & Human & Ubiquitination & RNF31 & Positive \\
\hline & Lys-383 & Human & Acetylation & Unknown & Positive \\
\hline & Lys-393 & Human & Acetylation & Unknown & Positive \\
\hline & Lys-393 & Human & Ubiquitination & RNF31 & Positive \\
\hline & Lys-393 & Mouse & Deubiquitination & USP7 & Positive \\
\hline & Lys-393 & Human & Deubiquitination & USP21 & Positive \\
\hline & Lys-416 & Human & Ubiquitination & RNF31 & Positive \\
\hline & Ser-418 & Human & Dephosphorylation & PP1 & Positive \\
\hline & Ser-422 & Human & Phosphorylation & PIM1 & Negative \\
\hline
\end{tabular}

FIGURE 1 | Protein domains, binding partners, and post-translational modification sites of Foxp3. (A) The relative structure of Foxp3 protein is shown in scales on the left. Four main domains are marked in different colors, namely repressor domain, zinc-finger (ZF) domain, leucine zipper (LZ) domain, and Fork-head (FHD) domain. (B) Main binding partners of Foxp3 are shown in the figure. Those with known binding sites are shown in their relative positions; those with unknown binding sites are listed in "unknown binding site". (C) For post-translational modifications (PTM) of Foxp3, the sites that are discussed in this review are listed in amino acid order. Besides, the species that are examined, the type of PTM, the modifier protein, and the role in regulating Foxp3 function are listed. Note that only those well-characterized sites are listed. Potential or uncertain sites are not included.

models (117). In addition, Smad2/3 binds to the Foxp3 locus in a temporal and spatial order. In brief, it first binds to the enhancer region of CNS1 and then dissociates from it in order to bind to the promoter binding element, which is about $-85 \mathrm{bp}$ upstream of the transcription start site $(105,118)$. Overall, Foxp3 is regulated by many important factors at the transcriptional level.

\section{Modification of Foxp3 Expression and Function at Post-Translational Level}

Post-translational modification (PTM) refers to enzymatic processes that alter a protein after its synthesis. These modifications will influence the characteristics of the protein, including its localization, interaction, turnover, etc. Given the importance of this factor and the $\mathrm{T}$ cell lineage it defines, Foxp3 
is, not surprisingly, tightly regulated by a number of mechanisms involving post-translational modifications. In this section, we will review some recent findings on post-translational modifications of Foxp3 (Figure 1C) and their roles in maintaining Foxp3 function and plasticity (Figure 2).

\section{Phosphorylation and Dephosphorylation}

Phosphorylation is a mechanism by which a protein kinase attaches a covalently bound phosphate group to the serine (S), threonine $(\mathrm{T})$, or tyrosine $(\mathrm{Y})$ residue of a protein. It is a reversible process as the protein can be dephosphorylated by phosphatases. These two modifications are important for protein function and stability. For Foxp3, more than 15 sites have been documented to be targets of phosphorylation. Among these, kinases CDK2, PIM1, and PIM2 negatively regulate Foxp3 functions; kinase NLK and phosphatase PP1 positively regulate Foxp3 function (119) (Figure 2A).

CDK2, PIM1, and PIM2 suppress Foxp3 function through different mechanisms. CDK2 is known to reduce Foxp3 stability. Along with cyclin E, CDK2 binds to four cyclin-dependent kinase motifs within the N-terminal domain of Foxp3 and causes phosphorylation of at least Ser-19 and Thr-175 (120). Such phosphorylation events lead to reduced Foxp3 protein stability and reduced Treg suppressive function (121). Intriguingly, PIM1 does not reduce Foxp3 stability but affects its DNA binding activity. Under inflammatory conditions, PIM1 phosphorylates Foxp3 at Ser-422 directly, which is located at the C-terminal region of the Fork-head domain (FHD) (122). Since the Fork-head domain is important for DNA binding, phosphorylated Ser-422 leads to reduced DNA binding. Likewise, PIM2 does not reduce Foxp3 stability but may affect its protein binding activity with other cofactors. PIM2 phosphorylates the N-terminal region of Foxp3, including at least Ser-33 and Ser-41 (123). These regions are important for binding with other cofactors like Eos, TIP60, and HDAC7, so phosphorylation at these sites may affect their binding activities $(123,124)$.

NLK and PP1 promote Foxp3 function through different mechanisms. NLK improves Foxp3 stability by preventing ubiquitin-dependent protein degradation of Foxp3. Upon TCR stimulation, TAK1-NLK signaling is activated (125). Then, NLK phosphorylates Foxp3 at seven distinct sites: Ser-19, Ser-156, Ser189, Ser-273, Ser-278, Ser-295, and Thr-341 (126). Such phosphorylation prevents its interaction with STUB1, an E3 ligase that induces K-48 polyubiquitination of Foxp3 (126). As for PP1, it protects Foxp3 function by improving DNA binding. Under inflammatory states, TNF- $\alpha$ induces an unknown kinase that phosphorylates Foxp3 at Ser-418 (127). Since Ser-418 resides in the Forkhead domain (FHD) and is critical for IL-2 regulation, dephosphorylation at Ser- 418 by PP1 protects the suppressive activity of Foxp3 (127).

\section{Acetylation and Deacetylation}

Acetylation is both a co-translational and a post-translational modification procuress that introduces an acetyl group into a protein by histone acetyltransferases (HTAs). This process can be reversed by histone deacetylases (HDACs). In regulatory $\mathrm{T}$ cells, acetylation and deacetylation of Foxp3 protein are mostly regulated by three HATs and nine HDACs with certain redundancy (128) (Figure 2B).

TIP60, p300, and CBP are the three HATs that regulate Foxp3 acetylation. Among these, CBP is a paralog of p300 and they perform critical but relatively redundant functions on Foxp3, based on double knockout experiments (129). Experiments have shown that p300 acetylates Foxp3 at multiples sites, including at least Lys-31, Lys-262, and Lys-267. These sites are critical for Foxp3 stability as they are also sites served for ubiquitindependent protein degradation (130). TIP60 regulates Foxp3 acetylation through multiple mechanisms. Firstly, it can form a binding complex with HDAC7 to promote Foxp3 acetylation and target the 106-190 aa repressor domain near the N-terminal region of Foxp3, which is important for IL-2 repression (131). Additionally, it can work cooperatively with p300 to enhance Foxp3 acetylation. It has been shown that p300 can facilitate the autoacetylation of TIP60 at Lys-327, allowing TIP60 to change binding partners to further enhance Foxp3 acetylation (132). Together, optimized Foxp3 acetylation shall be achieved in the presence of both TIP60 and p300 (for example, at Lys-179 and Lys-227) (133). Experiments have shown that losing either one of them leads to weak Foxp3 acetylation (132).

Besides direct acetylation by TIP60, p300, and CBP, it has been shown that Foxp3 structure can influence its interaction with HATs and vice versa. A recent study has shown that p.A384T FKH mutation on Foxp3 can disrupt the interaction between Foxp3 and TIP60, impairing the development and suppressive function of Treg cells (134). On the other hand, acetylation of Lys-250 and Lys-252 on Foxp3 by p300 leads to dimer relaxation and downregulates the suppressive function of Foxp3 (135). What is more, TGF $\beta$ induced Foxp3 acetylation and DNA binding are regulated by unknown mechanisms at Lys383 and Lys-393 (136, 137). Taken together, these demonstrate the importance of protein acetylation on Foxp3.

HDACs from five different subfamilies are involved in Foxp3 deacetylation, including HDAC1, 2, 3 from Class I, HDAC6, 7, 9 from Class IIA, HDAC10 from Class IIB, SIRT1 from Class III, and HDAC11 from Class IV. Among these, Class I HDACs are ubiquitously expressed by all cells. Experiments have shown that HDAC1 and HDAC2 bind to the N-terminal region of Foxp3 and counteract the hyper-acetylation of inflammation-related genes (69). HDAC3 interacts with SMRT/NCoR to form a functional complex in Treg cells. It associates with Foxp3 for optimal suppressive function, including suppressing IL-2 production (138). Class IIa HDACs have a restricted tissue distribution and they are expressed in lymphocytes. Upon inflammatory conditions, HDAC6 deacetylates both Foxp3 and HSP90, preventing them from forming a complex (139). The direct role of HDAC6 in regulating Foxp3 protein interaction and function is yet unclear, but recent experiments have shown that deacetylation of HSP90 affects many client proteins, including HSF1. Additionally, deletion of HDAC6 in Treg cells would increase the expression of many Treg-associated genes, including IL-10, Lag3, STAT3, and decrease IL-2, which 


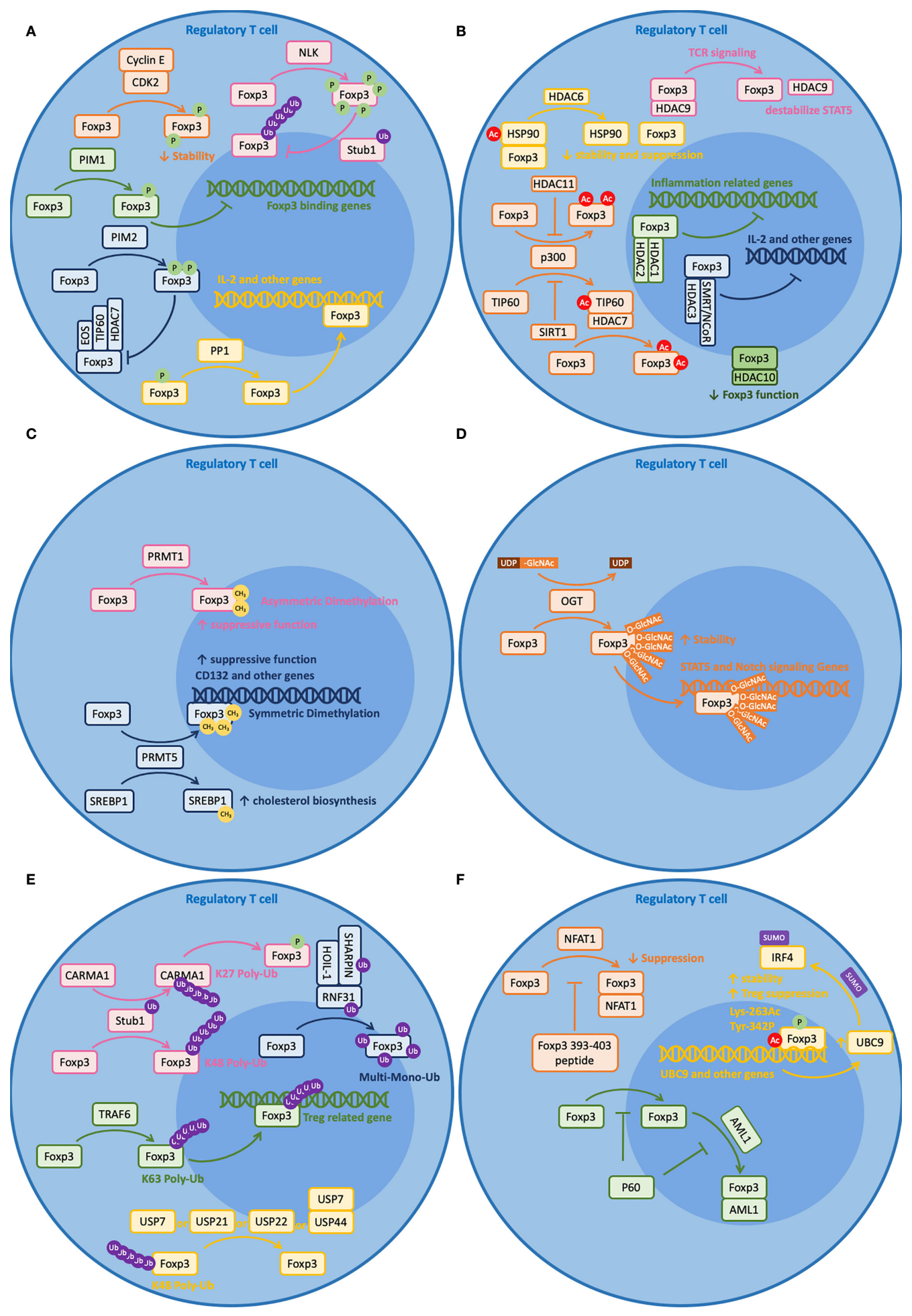

FIGURE 2 | Post-translational modifications (PTM) of Foxp3. Foxp3 can be post-transcriptionally modified by a variety of regulators. Brief illustrations are shown here to outline their basic mechanisms. (A) Phosphorylation (CDK2, PIM1, PIM2, NLK) and dephosphorylation (PP1) of Foxp3. (B) Acetylation (p300 and TIP60) and deacetylation (HDAC1, 2, 3, 6, 7, 9, 10, 11, and SIRT1) of Foxp3. (C) Methylation (PRMT1 and PRMT5) of Foxp3. (D) Glycosylation (OGT) of Foxp3.

(E) Ubiquitination (RNF31, Stub1, and TRAF6) and deubiquitination (USP7, 21, 22, and 44) of Foxp3. (F) Other modifications, including peptides (Foxp3 393-403 peptide and P60) that regulate Foxp3 and SUMOlyation (UBC9) that is regulated by PTM modified Foxp3. 
significantly improves Treg stability and suppressive function $(139,140)$. Besides the role of forming functional complex with TIP60 and Foxp3 (131), the HDAC7 complex is also associated with the repression of Nur77, which regulates the balance between Teff and Treg cells and the stability of Treg cells (141). Despite the direct role of deacetylating Foxp3, upon TCR-induced cell signaling, HDAC9 dissociates from Foxp3 and disrupts the acetylation of STAT5, which negatively regulates Foxp3 function $(131,136,142)$. As a Class IIB HDAC, HDAC10 also interacts with Foxp3 directly and reduces the suppressive function of Foxp3. In vitro experiments show that HDAC10 promotes the deacetylation of Foxp3 at Lys-31. However, the detailed mechanism remains elusive (143). Different from the other HDACs, SIRT1 is NAD-dependent, and it inhibits the autoacetylation of TIP60, which negatively regulates the acetylation of Foxp3 $(144,145)$. Lastly, as the only member of Class IV $\mathrm{Zn}^{2+}$-dependent HDAC, HDAC11 coassociates with Foxp3 in the nucleus and promotes p300dependent deacetylation of Foxp3. Besides, it has been reported to regulate the suppressive function of Foxp3 in vitro through a TGF- $\beta$-dependent mechanism by regulating the expression of Treg-associated genes (146).

\section{Methylation}

Protein methylation is a common type of post-transcriptional modification that adds methyl groups to a protein, commonly on arginine and lysine residues (147). Recent studies have reported that two arginine methyltransferase (PRMT) family members, PRMT1 and PRMT5, are critical for Foxp3 protein methylation (119) (Figure 2C).

In detail, PRMT1 leads to asymmetrical dimethylarginines on Arg-48 and Arg-51 of Foxp3 (148). Inhibiting the methylation of these two sites simultaneously leads to reduced suppressive function of Treg cells and increased Th1-associated gene expression profiles in Foxp $3^{+} \mathrm{T}$ cells (148). Using MS023 [a type 1 protein arginine methyltransferase (PRMT) inhibitor]treated WT Foxp3+ T cells and Foxp3 R48/51A-transduced T cells, these authors suggested that repressing the Th1 phenotype through an AKT-dependent signaling abrogates the effect of arginine methylation inhibition on the suppressive activity of Foxp3 + T cells (148). Interestingly, another study showed that PRMT1 is also important for differentiation of Th17 cells by associating with ROR $\gamma t$ and regulating the reciprocal recruitment of STAT3 and STAT5. These authors showed that overexpression of PRMT1 promotes Th17 differentiation and inhibition of PRMT1 expands Foxp $3^{+}$Treg cells population (149). Taken together, these two studies reveal the role of PRMT1 in regulating Foxp3 function and Treg plasticity.

Likewise, PRMT5 catalyzes symmetric dimethylarginines on Arg-27, Arg-51 and Arg-146 of Foxp3 (150), which are confirmed using point mutation experiment and mass spectrometry. Among these, methylation on Arg-51 is critical for the suppressive function of Foxp3. Conditionally knocking out PRMT5 in mouse Foxp $3^{+}$cells lead to reduced numbers of Treg cells in the spleen but not in peripheral lymph nodes (150). In addition, silencing PRMT5 in these Foxp3+ cells resulted in limited suppressive function, demonstrating the importance of
PRMT5 in maintaining Treg functions. Additionally, human CD4+T cells transfected with Foxp3 R51K, a mutant lacking dimethylation site modified by PRMT5 showed reduced suppressive functions compared to those with vector encoding wild type Foxp3 (150). A more recent study demonstrated that PRMT5 is not required for thymic development of T cells before the double positive (DP) stage (151). However, the factor is critical for peripheral $\mathrm{T}$ cell survival, naïve to effector/memory transition, and TCR-induced proliferation. One of the potential mechanisms responsible for these observations involves RPMT5 regulation of the expression of the common gamma chain (CD132) of IL-2 receptor (151). Besides, PRMT5 modulates Th17 differentiation via the methylation of SREBP1, which regulates cholesterol biosynthesis (152). Taken together, both PRMT5 and PRMT1 are critical in regulating Foxp3 function and plasticity.

\section{Glycosylation}

Glycosylation is a form of co-translational and post-translational modifications that attaches glycans to proteins (153). As a rising field in biological studies, protein glycosylation has shown important effects on $\mathrm{T}$ cell development, activation, and differentiation (153). Some studies have shown that the surface glycosylation patterns of regulatory $\mathrm{T}$ and conventional $\mathrm{T}$ cells are very different $(154,155)$. Interestingly, surface levels of tri/ tetra-antennary $\mathrm{N}$-glycans on Treg cells correlates with the expression level of suppressive ligands, including GITR, PD-1, PD-L1, CD73, CTLA-4, and ICOS. Further experiments have suggested a positive correlation between glycosylation and the suppressive activity of Treg cells (154).

Recently, it has been shown that Foxp3 can be modified by TCR-activated O-linked N-Acetylglucosamine (O-GlcNAc) at multiple sites, including Thr-38, Ser-57, Ser-58, Ser-270, and Ser273 (156). Using Treg cells from inducible O-GlcNAc transferase (OGT) knockout mice (Ubc-Cre/ERT2 ${ }^{+} \mathrm{Ogt}^{\mathrm{fl} / \mathrm{Y}}$ ), these authors showed that loss of O-GlcNAcylation destabilizes Foxp3 protein in Treg cells ex vivo. Furthermore, using liquid chromatography with tandem mass spectrometry (LC-MS/MS) through electron transfer dissociation (ETD), these authors further found the above O-GcNAc sites using HEK293 cells expressing Foxp3. Although $O$-GlcNAc-deficient Treg cells develop normally in mice (Foxp3 ${ }^{\mathrm{YFP}-\mathrm{Cre} / \mathrm{Y}} \mathrm{Ogt}^{\mathrm{fl} / \mathrm{Y}}$ ), their Foxp3 expression level is moderately decreased and their suppressive function is significantly impacted partially due to attenuated IL-2/STAT5 and Notch signaling $(156,157)$. Besides the role of O-GlcNAc on Foxp3, it also affects the activation and function of c-Rel, which is a critical NFKB subunit that regulates Foxp3 transcription (158, 159) (Figure 2D).

\section{Ubiquitination and Deubiquitination}

Ubiquitination is a type of post-translational modification that attaches ubiquitin molecules to the target protein (160). It is an ATP-dependent regulation that involves three adapter proteins, namely E1 (ubiquitin-activating enzyme), E2 (ubiquitinconjugating enzyme), and E3 (ubiquitin ligase). The substrate protein can be either monoubiquitinated or polyubiquitinated. While monoubiquitination normally involves cell signaling and 
membrane trafficking, polyubiquitination involves many different functions. Among the eight different types of polyubiquitination (K6, K11, K27, K29, K33, K48, K63, and M1), K48 polyubiquitination leads to proteasome-dependent protein degradation and K63 polyubiquitination involves cell signaling (161). Ubiquitination is a reversible process and it can be reversed by deubiquitinases (DUB), which remove ubiquitin tags from the substrate protein (162).

In Treg cells, RNF31, Stub1, and TRAF6 are the three E3 ligases that directly ubiquitinate Foxp3 (Figure 2E). Interestingly, they mediate different types of ubiquitination that lead to different functions. For example, RNF31 leads to monoubiquitination on Foxp3. In brief, RNF31 is a RING-type E3 ligase of LUBAC (linear ubiquitin chain assembly complex) (163). It is auto-inhibited before binding with the other two proteins of LUBAC, namely HOIL-1, and SHARPIN $(164,165)$. The complex regulates linear polyubiquitination and is important for multiple immune pathways, including TCR, BCR, NOD, TLR, and TNFR signaling pathways (166-172). In Treg cells, RNF31 not only regulates TCR signaling but also regulates multiple monoubiquitinations on Foxp3, including Lys-31, Lys-200, Lys-250, Lys-263, Lys-268, Lys-382, Lys-393, and Lys-416 (173). These atypical ubiquitin chains lead to improved Foxp3 protein level and enhanced suppressive functions $(173,174)$.

Unlike RNF31, which mediates monoubiquitination, Stub1 and TRAF6 regulate polyubiquitination on Foxp3. Stub1 is a Ubox type E3 ligase that interacts with HSP70 (175). When challenged with stress signals like LPS and proinflammatory cytokines, Stub1 mediates K48 polyubiquitination on Foxp3 at multiple sites, including at least Lys-227, Lys-250, Lys-263, and Lys-268 (176). Such ubiquitination leads to proteasomedependent Foxp3 degradation and thus reduced suppressive activity (176). Additionally, Stub1 leads to K27 polyubiquitination on CARMA1 at Lys-689 and Lys-696, which facilitates the activation of the NFKB pathway (177). Distinct from the action of Stub1, which leads to Foxp3 degradation, TRAF6 regulates Foxp3 localization. TRAF6 is a RING-type E3 ligase that mediates inflammation-related signals, including IL1R, TLR, and TNFR superfamily signaling (178). Studies from our group have shown that TRAF6 mediates K63 polyubiquitination on Foxp3 at Lys-262, which does not interfere with other K48 polyubiquitination (179). The mechanism behind this is that TRAF6 regulates the nuclear transport of Foxp3 as deficiency of TRAF6 leads to aberrant accumulation of Foxp3 in the cytoplasm (our unpublished data). Together, these studies illustrate the importance and versatility of E3 ligases in regulating Foxp3 stability and function.

As the Janus side of ubiquitination, deubiquitination also plays important roles in regulating Foxp3 function and plasticity. Among nearly 100 DUBs reported so far (162), USP7, USP21, USP22, and USP44 have shown direct interaction with Foxp3 (Figure 2E). USP7 preserves Foxp3 homeostasis by removing K48-type polyubiquitination tags at Lys-249, Lys-251, Lys-263, Lys-267, and Lys-393 (180). Thus, USP7 prevents Foxp3 from ubiquitin-dependent protein degradation and enhances the interaction between Foxp3 and TIP60, which preserves its expression level $(180,181)$. Similarly, USP21 prevents Foxp3 degradation by deubiquitinating K48-type modifications at residues Lys-206, Lys-216, Lys-227, Lys-252, Lys-277, Lys-332, and Lys-393 (182). The action of USP21 also appears to play a role in a feedback loop with Foxp3 $(183,184)$. Upon TCR stimulation, Foxp3 activates the transcription of the Usp21 gene. Then, USP21 prevents Foxp3 degradation, which further enhances the transcription of Usp21 and suppresses Th1-like phenotypes $(182,183)$. Likewise, USP22 interacts with Foxp3 and prevents its degradation (90). Recently, a study from our group showed that USP44 also interacts with Foxp3 and prevents its degradation by deubiquitinating K48-type polyubiquitin chains on Foxp3 (185]. During iTreg differentiation, TGF- $\beta$ signaling induces USP44 upregulation. Then, USP 44 cooperates with USP7 to stabilize and deubiquitinate Foxp3 (185). Together, these DUBs play important roles in maintaining Foxp3 homeostasis and show great therapeutic potentials as drug targets.

\section{Others}

Besides the natural post-translational modifications reviewed above, Foxp3 binding peptides may function as artificial PTMs and are worth discussing. These binding peptides can be either pieces of the Foxp3 amino acid sequence competing for the binding partners and co-factors of Foxp3, or random peptides that block critical Foxp3 functions. So far, two peptides have been carefully studied regarding their roles in regulating Foxp3 functions. First, Foxp3 393-403 peptide can interact with the RHR domain of NFAT1, disrupting of the Foxp3/NFAT1 interaction-a molecular pairing that is thought to regulate Treg-associated genes. Such inhibition reduces Treg suppression and may be useful for tumor immunotherapies (186). Another 15-mer peptide, named P60, originates from a phage-display peptide screening. P60 can enter the cell, inhibit Foxp3 nuclear transportation, and impedes Foxp3 dimerization and Foxp3/AML1 interaction $(186,187)$ (Figure 2F). These findings suggest good therapeutic potential of artificial posttranslational modifications of Foxp3.

In addition to post-translational regulations of Foxp3, modified Foxp3 can play a critical role in regulating other PTMs, for example, SUMOylation. Similar to ubiquitination, SUMOylation tags small ubiquitin-like modifiers (SUMO) to the substrate for multiple functions, including cell signaling and protein turnover (188). As the only E2 conjugating enzyme involved in SUMOylation, UBC9 has been reported recently to play a critical role in maintaining Treg suppression by enhancing IRF4 SUMOylation. Such SUMOylation would prevent IRF4 from proteasome degradation $(189,190)$. As a transcriptional activator of UBC9, Foxp3 binds to the UBC9 promoter and regulates its activation. Furthermore, de-acetylation/ ubiquitination at Lys-263 and dephosphorylation at Tyr-342 of Foxp3 would severely impede UBC9 transcription (189), suggesting an important role of Foxp3 PTM in regulating Foxp3 functions (Figure 2F). 


\section{TREG CELLS IN CLINICAL APPLICATIONS}

As a rising field in its own right, the therapeutic use and modulation of Treg cells can have major clinical applications in the treatment of autoimmune diseases, transplantation, cancer, as well as colitis and other inflammatory diseases. So far, 1,010 clinical trials involving Treg cells have been documented at the NIH. In addition, hundreds of small molecules drugs, antibodies, and other nanoparticles have been designed to target Treg cells directly or indirectly, indicating the broad range of potential applications involving Treg cells (191). In this section, we will review some of the most recent advances in the clinical manipulation of Tregs and provide some potential therapeutic drugs that may worth further investigations.

\section{Autoimmune Diseases}

In brief, autoimmune diseases occur when the immune system mistakenly targets self. Some common autoimmune diseases include Lupus, Celiac disease, Sjogren's syndrome, Multiple sclerosis, Polymyalgia rheumatica, Type 1 diabetes (T1D), and rheumatoid arthritis (RA) (192). Of note, deficiency or dysfunction of Treg cells is considered to be the leading cause of these diseases. For example, patients suffered from IPEX syndrome have FOXP3 mutations that leads to a reduction of the number of Foxp3+ Treg cells (10); many RA patients have relatively normal number of Treg cells, but a lot of them show impaired suppression of self-antigens (193).

To resolve these issues, many clinical trials are focusing on augmenting functionally suppressive Treg cells for these patients. One way is to select polyclonal autologous T cells, expand iTreg cells ex vivo, and then infuse them back to patients. Many trials have been performed using this approach to treat patients with T1D and lupus, including, NCT02772679, NCT02932826, NCT02704338, and NCT02428309 (194).

\section{Transplantation}

Despite established surgical techniques of organ transplantation, long-term tolerance to an allogeneic organ is still challenging. One current approach to prevent graft vs host disease (GvHD) is to use immunosuppressants to down-regulate normal immune functions, including using anti-proliferative agents, steroids, mTOR inhibitors, and Calcineurin inhibitors (195). However, systemic immunosuppression can lead to many side effects, making patients susceptible to infectious diseases and cancer (196).

For these reasons, chimeric antigen receptor Treg (CARTreg) therapy attracts a lot of attentions (197, 198). Since MHC I is critical for immune tolerance and HLA-A2 is highly prevalent in white human donors $(199,200)$, HLA-A2-specific CAR-Treg (A2-CAR-Treg) was generated and examined in mouse models. Surprisingly, in a skin allograft model, NOD.Rag1 ${ }^{\text {null }} . I L 2 \mathrm{rg}^{\text {null }}$ (NRG) mice receiving A2-CAR-Treg cells showed much stronger tolerance induction than those receiving polyclonal nTreg or controls (201). Therefore, antigen-specific Treg therapy cells hold a promising future for patients that require transplantation.

\section{Cancer}

While important for maintaining immune homeostasis, Treg cells are known to play a pathological role in cancer patients by impeding desirable anti-tumor immunity (202). They readily accumulate within tumors and suppress the activity of tumorreactive cytotoxic immune cells, leading to uncontrolled expansion and migration of malignant cells (203). Therefore, strategies to deplete or inhibit intratumoral Treg cells are being pursued to improve the therapeutic outcome.

As a proven weapon in the anti-cancer arsenal, checkpoint inhibitor immunotherapies are being used to maintain and boost the function of cytotoxic T cells (204). From the clinical perspective, blocking antibodies, including ipilimumab (antiCTLA-4), nivolumab (anti-PD-1), and pembrolizumab (antiPD-1) have been widely approved to treat many types of cancers (205). Since the ligands of these checkpoints, including PD-1, CTLA-4, are expressed by Treg cells at high levels (206, 207), blocking these checkpoints are also expected to regulate the plasticity of suppressive function of Treg cells $(23,208-210)$. So far, many theories have been proposed to explain the therapeutic effects of checkpoint inhibitors on Tregs, and they offer explanations for the distinct effects of checkpoint inhibitors on Treg cells and non-Treg cells. First, the anti-CTLA-4 antibody blocks Treg cells from downregulating the B7 ligands on APCs, which leads to reduced CD28 co-stimulation $(211,212)$. It also prevents the co-inhibitory CTLA-4: B7 binding on Tconv cells, which promotes the activation of Tconv cells $(213,214)$. Second, the anti-PD-1 antibody prevents the conversion of TBET+ Th1 cells into Foxp3+ Treg cells in vivo (215). Additionally, it prevents the PD-1: PD-L1 binding between tumor-infiltrating lymphocytes and tumor cells, which restores the antitumor immunity $(23,216,217)$.

Drugs specifically targeting Foxp3 PTM also represent high potential strategies for combating immune suppression in cancer as they are not likely to affect the function of Tconv cells and CTLs. As reviewed in the post-translational modification sections, preventing the acetylation, DNA binding, or dimerization of Foxp3 are potentially useful approaches to suppress Treg cells. Thus, preclinical studies using USP7 inhibitors (181), p300 inhibitors (218), P60 peptide (187), PMRT5 inhibitors (150), and PROTACs (219) may be promising.

\section{Colitis and Other Inflammation Associated Diseases}

We are challenged by a variety of potential pathogens at all times, including bacteria, viruses, and fungi (220). To maintain tissue homeostasis, Treg cells play an important role in developing $\mathrm{T}$ cell memory and prevention of reinfection, especially in gastrointestinal and respiratory systems (221). Impaired Treg function or plasticity can lead to chronic inflammation (222). For example, dysfunctional Treg cells can underlie the development of inflammatory bowel disease (IBD) that can also leads to colitis-associated colon carcinoma (CA-CRC) in the long run (222). 
Some factors are known to restrict Treg functions, including chronic exposure to inflammatory cytokines and deprivation of stabilizing factors. Chronic exposure of Tregs to proinflammatory cytokines like IL-1 $\beta$, IL-6, TNF $\alpha$, which can antagonize Foxp3 expression and skews the gene expression profile to that of Th17 or Th1 (223-225). Reduced levels of IL2 and TGF $\beta(116,226)$, on the other hand, can adversely affect the survival of Treg cells. Therefore, besides anti-inflammatory drugs which relieve colitis symptoms (227), drugs stabilizing and enhancing Foxp3 function may also be useful, such as HADC6 and HADC9 inhibitors (228).

\section{SUMMARY AND FUTURE PERSPECTIVE}

After decades of intensive studies, our knowledge of Treg cells has improved significantly. With increasing regulatory mechanisms of Foxp3 being brought to light, the potential of manipulating Foxp3 at the post-translational level has increased dramatically. At this stage, we believe two aspects will be important for future drug discovery: first, an in vivo, highthroughput target screening assay for agents capable of disrupting the posttranslational means of supporting Foxp3 expression and function and the stronger suppressive potency of Treg cells, and second, a high-throughput and cost-efficient pre-clinical drug examination platform for Treg-based therapies. While the former requires more accurate and efficient CRISPRbased gene-editing techniques to be applied to Treg cells, the latter aspect will benefit from new screening systems. On the one hand, murine disease models are still very different from human cases due to evolutionary heterogeneities (229). On the other hand, macaque models are very expensive, time-consuming, and less quantitative due to the limited sample size (230). Besides, a lot of ethical regulations limited the use of primates (231), making it difficult for high-throughput experiments. In this case, using organoids and microfluidic techniques may be a compromise. Since organoids are derived from human stem cells, they can mimic certain functions of human organs ex vivo (232). Moreover, microfluidic devices can provide $3 \mathrm{D}$ structures for immune cells, bacteria, viruses, and organoids to contact with each other, which may represent in situ interactions (233). Thus, 3D ex vivo culture systems showed great promise in drug development.

\section{REFERENCES}

1. Flajnik MF, Kasahara M. Origin and evolution of the adaptive immune system: genetic events and selective pressures. Nat Rev Genet (2010) 11 (1):47-59. doi: $10.1038 / \mathrm{nrg} 2703$

2. Mueller DL. Mechanisms maintaining peripheral tolerance. Nat Immunol (2010) 11(1):21-7. doi: 10.1038/ni.1817

3. Sakaguchi S, Yamaguchi T, Nomura T, Ono M. Regulatory T cells and immune tolerance. Cell (2008) 133(5):775-87. doi: 10.1016/j.cell.2008.05.009

4. Nishizuka Y, Sakakura T. Thymus and reproduction: sex-linked dysgenesia of the gonad after neonatal thymectomy in mice. Science (1969) 166 (3906):753-5. doi: 10.1126/science.166.3906.753
Another equally important issue is how to improve Tregspecific targeting. Currently, most strategies targeting Treg cells use monoclonal antibodies or ligand-directed toxins to deplete Treg cells systemically or locally (234). However, such strategies do not fit all disease conditions, especially autoimmune diseases and other inflammation-associated diseases. Like other cell-typespecific drugs, a biochemistry-based, bioinformatics-guided designing platform is needed to achieve Treg-specific targeting. To do so, the effective first step is to prevent targeting the isoforms of the target protein. For example, treatment of a class I/II HDAC inhibitor, Trichostain A (TSA), increased the percentage of Treg cells and their suppressive activities (136). A later experiment shows that the main effects were caused by inhibiting the class IIb HDACs (e.g., tubastatin A) (228). Since both HDAC6 and HDAC10 belongs to class IIb HDAC and HDAC6 has been demonstrated to play more important roles in Treg functions in vivo (235), a specific inhibitor for HDAC6 may provide the optimum therapeutic outcome in the future. Another important way to achieve Treg specificity is to target proteins with relatively unique functions and pathways. In this regard, E3 ligases would be excellent candidates since there are nearly 500-1,000 of them in human and many of them have unique functions in specific tissues or cell types (236). Moreover, it is tempting to use nanoparticles to achieve Treg specificity. Many recent studies have used specifically designed particles as carriers to present antigens or deliver drugs to Treg cells (237-240), which suggests that small-molecule inhibitors against PTM enzymes can also be used for future drug designs. Above all, we believe strongly that investigating post-translational modifications of Foxp3 will reveal more therapeutic potentials in the future and new techniques will facilitate the drug discovery.

\section{AUTHOR CONTRIBUTIONS}

All authors listed have made a substantial, direct, and intellectual contribution to the work and approved it for publication.

\section{FUNDING}

This work was supported by the start-up package from SIAT, no. 1105161001.

5. Gershon RK, Kondo K. Cell interactions in the induction of tolerance: the role of thymic lymphocytes. Immunology (1970) 18(5):723-37.

6. Sakaguchi S, Sakaguchi N, Asano M, Itoh M, Toda M. Immunologic selftolerance maintained by activated $\mathrm{T}$ cells expressing IL-2 receptor alphachains (CD25). Breakdown of a single mechanism of self-tolerance causes various autoimmune diseases. J Immunol (1995) 155(3):1151-64. doi: 10.3410/f.1002182.10858

7. Asano M, Toda M, Sakaguchi N, Sakaguchi S. Autoimmune disease as a consequence of developmental abnormality of a T cell subpopulation. J Exp Med (1996) 184(2):387-96. doi: 10.1084/jem.184.2.387

8. Brunkow ME, Jeffery EW, Hjerrild KA, Paeper B, Clark LB, Yasayko SA, et al. Disruption of a new forkhead/winged-helix protein, scurfin, results in 
the fatal lymphoproliferative disorder of the scurfy mouse. Nat Genet (2001) 27(1):68-73. doi: 10.1038/83784

9. Wildin RS, Ramsdell F, Peake J, Faravelli F, Casanova JL, Buist N, et al. Xlinked neonatal diabetes mellitus, enteropathy and endocrinopathy syndrome is the human equivalent of mouse scurfy. Nat Genet (2001) 27 (1):18-20. doi: $10.1038 / 83707$

10. Bennett CL, Christie J, Ramsdell F, Brunkow ME, Ferguson PJ, Whitesell L, et al. The immune dysregulation, polyendocrinopathy, enteropathy, Xlinked syndrome (IPEX) is caused by mutations of FOXP3. Nat Genet (2001) 27(1):20-1. doi: 10.1038/83713

11. Hori S, Nomura T, Sakaguchi S. Control of regulatory T cell development by the transcription factor Foxp3. Science (2003) 299(5609):1057-61. doi: $10.1126 /$ science. 1079490

12. Fontenot JD, Gavin MA, Rudensky AY. Foxp3 programs the development and function of CD4+CD25+ regulatory T cells. Nat Immunol (2003) 4 (4):330-6. doi: 10.1038/ni904

13. Khattri R, Cox T, Yasayko SA, Ramsdell F. An essential role for Scurfin in CD4+CD25+ T regulatory cells. Nat Immunol (2003) 4(4):337-42. doi: $10.1038 /$ ni909

14. Nosbaum A, Prevel N, Truong HA, Mehta P, Ettinger M, Scharschmidt TC, et al. Cutting Edge: Regulatory T Cells Facilitate Cutaneous Wound Healing. J Immunol (2016) 196(5):2010-4. doi: 10.4049/jimmunol.1502139

15. Kikuchi K. New function of zebrafish regulatory $\mathrm{T}$ cells in organ regeneration. Curr Opin Immunol (2020) 63:7-13. doi: 10.1016/ j.coi.2019.10.001

16. Hui SP, Sheng DZ, Sugimoto K, Gonzalez-Rajal A, Nakagawa S, Hesselson D, et al. Zebrafish Regulatory $\mathrm{T}$ Cells Mediate Organ-Specific Regenerative Programs. Dev Cell (2017) 43(6):659-72.e5. doi: 10.1016/j.devcel.2017.11.010

17. Campbell C, Rudensky A. Roles of Regulatory T Cells in Tissue Pathophysiology and Metabolism. Cell Metab (2020) 31(1):18-25. doi: 10.1016/j.cmet.2019.09.010

18. Li J, Tan J, Martino MM, Lui KO. Regulatory T-Cells: Potential Regulator of Tissue Repair and Regeneration. Front Immunol (2018) 9:585. doi: 10.3389/ fimmu.2018.00585

19. Sharma A, Rudra D. Emerging Functions of Regulatory T Cells in Tissue Homeostasis. Front Immunol (2018) 9:883. doi: 10.3389/fimmu.2018.00883

20. Read S, Malmstrom V, Powrie F. Cytotoxic T lymphocyte-associated antigen 4 plays an essential role in the function of $\mathrm{CD} 25(+) \mathrm{CD} 4(+)$ regulatory cells that control intestinal inflammation. J Exp Med (2000) 192(2):295-302. doi: 10.1084/jem.192.2.295

21. Oderup C, Cederbom L, Makowska A, Cilio CM, Ivars F. Cytotoxic T lymphocyte antigen-4-dependent down-modulation of costimulatory molecules on dendritic cells in $\mathrm{CD} 4+\mathrm{CD} 25+$ regulatory T-cell-mediated suppression. Immunology (2006) 118(2):240-9. doi: 10.1111/j.13652567.2006.02362.x

22. Liang B, Workman C, Lee J, Chew C, Dale BM, Colonna L, et al. Regulatory $\mathrm{T}$ cells inhibit dendritic cells by lymphocyte activation gene-3 engagement of MHC class II. J Immunol (2008) 180(9):5916-26. doi: 10.4049/ jimmunol.180.9.5916

23. Gianchecchi E, Fierabracci A. Inhibitory Receptors and Pathways of Lymphocytes: The Role of PD-1 in Treg Development and Their Involvement in Autoimmunity Onset and Cancer Progression. Front Immunol (2018) 9:2374. doi: 10.3389/fimmu.2018.02374

24. Hilchey SP, De A, Rimsza LM, Bankert RB, Bernstein SH. Follicular lymphoma intratumoral $\mathrm{CD} 4+\mathrm{CD} 25+\mathrm{GITR}+$ regulatory $\mathrm{T}$ cells potently suppress $\mathrm{CD} 3 / \mathrm{CD} 28$-costimulated autologous and allogeneic CD8+CD25and CD4+CD25- T cells. J Immunol (2007) 178(7):4051-61. doi: 10.4049/ jimmunol.178.7.4051

25. Vignali DA, Collison LW, Workman CJ. How regulatory T cells work. Nat Rev Immunol (2008) 8(7):523-32. doi: 10.1038/nri2343

26. Luo CT, Li MO. Transcriptional control of regulatory T cell development and function. Trends Immunol (2013) 34(11):531-9. doi: 10.1016/ j.it.2013.08.003

27. Bjur E, Larsson O, Yurchenko E, Zheng L, Gandin V, Topisirovic I, et al. Distinct translational control in CD4+ T cell subsets. PloS Genet (2013) 9(5): e1003494. doi: 10.1371/journal.pgen.1003494
28. Gao M, Karin M. Regulating the regulators: control of protein ubiquitination and ubiquitin-like modifications by extracellular stimuli. Mol Cell (2005) 19 (5):581-93. doi: 10.1016/j.molcel.2005.08.017

29. Bielskiene K, Bagdoniene L, Mozuraitiene J, Kazbariene B, Janulionis E. E3 ubiquitin ligases as drug targets and prognostic biomarkers in melanoma. Med (Kaunas) (2015) 51(1):1-9. doi: 10.1016/j.medici.2015.01.007

30. Hori S. Stability of regulatory T-cell lineage. Adv Immunol (2011) 112:1-24. doi: 10.1016/B978-0-12-387827-4.00001-2

31. Miyara M, Yoshioka Y, Kitoh A, Shima T, Wing K, Niwa A, et al. Functional delineation and differentiation dynamics of human $\mathrm{CD} 4+\mathrm{T}$ cells expressing the FoxP3 transcription factor. Immunity (2009) 30(6):899-911. doi: 10.1016/j.immuni.2009.03.019

32. Curotto de Lafaille MA, Lafaille JJ. Natural and adaptive foxp3+ regulatory T cells: more of the same or a division of labor? Immunity (2009) 30(5):626-35. doi: 10.1016/j.immuni.2009.05.002

33. Chen W, Jin W, Hardegen N, Lei KJ, Li L, Marinos N, et al. Conversion of peripheral $\mathrm{CD} 4+\mathrm{CD} 25$ - naive $\mathrm{T}$ cells to $\mathrm{CD} 4+\mathrm{CD} 25+$ regulatory $\mathrm{T}$ cells by TGF-beta induction of transcription factor Foxp3. J Exp Med (2003) 198 (12):1875-86. doi: 10.1084/jem.20030152

34. Zheng SG, Gray JD, Ohtsuka K, Yamagiwa S, Horwitz DA. Generation ex vivo of TGF-beta-producing regulatory $\mathrm{T}$ cells from $\mathrm{CD} 4+\mathrm{CD} 25-$ precursors. J Immunol (2002) 169(8):4183-9. doi: 10.4049/ jimmunol.169.8.4183

35. Davidson TS, DiPaolo RJ, Andersson J, Shevach EM. Cutting Edge: IL-2 is essential for TGF-beta-mediated induction of Foxp $3+\mathrm{T}$ regulatory cells. J Immunol (2007) 178(7):4022-6. doi: 10.4049/jimmunol.178.7.4022

36. Zheng SG, Wang J, Wang P, Gray JD, Horwitz DA. IL-2 is essential for TGFbeta to convert naive $\mathrm{CD} 4+\mathrm{CD} 25-$ cells to $\mathrm{CD} 25+\mathrm{Foxp} 3+$ regulatory $\mathrm{T}$ cells and for expansion of these cells. J Immunol (2007) 178(4):2018-27. doi: 10.4049/jimmunol.178.4.2018

37. Ouyang W, Beckett $\mathrm{O}, \mathrm{Ma} \mathrm{Q}$, Li MO. Transforming growth factor-beta signaling curbs thymic negative selection promoting regulatory $\mathrm{T}$ cell development. Immunity (2010) 32(5):642-53. doi: 10.1016/ j.immuni.2010.04.012

38. Thorstenson KM, Khoruts A. Generation of anergic and potentially immunoregulatory $\mathrm{CD} 25+\mathrm{CD} 4 \mathrm{~T}$ cells in vivo after induction of peripheral tolerance with intravenous or oral antigen. J Immunol (2001) 167(1):188-95. doi: 10.4049/jimmunol.167.1.188

39. Apostolou I, von Boehmer H. In vivo instruction of suppressor commitment in naive T cells. J Exp Med (2004) 199(10):1401-8. doi: 10.1084/ jem.20040249

40. Cobbold SP, Castejon R, Adams E, Zelenika D, Graca L, Humm S, et al. Induction of foxP3+ regulatory $\mathrm{T}$ cells in the periphery of $\mathrm{T}$ cell receptor transgenic mice tolerized to transplants. J Immunol (2004) 172(10):6003-10. doi: 10.4049/jimmunol.172.10.6003

41. Mucida D, Kutchukhidze N, Erazo A, Russo M, Lafaille JJ, Curotto de Lafaille MA. Oral tolerance in the absence of naturally occurring Tregs. J Clin Invest (2005) 115(7):1923-33. doi: 10.1172/JCI24487

42. Zheng SG, Wang JH, Stohl W, Kim KS, Gray JD, Horwitz DA. TGF-beta requires CTLA- 4 early after T cell activation to induce FoxP3 and generate adaptive CD4+CD25+ regulatory cells. J Immunol (2006) 176(6):3321-9. doi: 10.4049/jimmunol.176.6.3321

43. Lu L, Ma J, Li Z, Lan Q, Chen M, Liu Y, et al. All-trans retinoic acid promotes TGF-beta-induced Tregs via histone modification but not DNA demethylation on Foxp3 gene locus. PloS One (2011) 6(9):e24590. doi: 10.1371/journal.pone. 0024590

44. Round JL, Mazmanian SK. Inducible Foxp3+ regulatory T-cell development by a commensal bacterium of the intestinal microbiota. Proc Natl Acad Sci USA (2010) 107(27):12204-9. doi: 10.1073/pnas.0909122107

45. Atarashi K, Tanoue T, Shima T, Imaoka A, Kuwahara T, Momose Y, et al. Induction of colonic regulatory $\mathrm{T}$ cells by indigenous Clostridium species. Science (2011) 331(6015):337-41. doi: 10.1126/science.1198469

46. Geuking MB, Cahenzli J, Lawson MA, Ng DC, Slack E, Hapfelmeier S, et al. Intestinal bacterial colonization induces mutualistic regulatory $\mathrm{T}$ cell responses. Immunity (2011) 34(5):794-806. doi: 10.1016/ j.immuni.2011.03.021 
47. Jordan MS, Boesteanu A, Reed AJ, Petrone AL, Holenbeck AE, Lerman MA, et al. Thymic selection of $\mathrm{CD} 4+\mathrm{CD} 25+$ regulatory $\mathrm{T}$ cells induced by an agonist self-peptide. Nat Immunol (2001) 2(4):301-6. doi: 10.1038/86302

48. Relland LM, Mishra MK, Haribhai D, Edwards B, Ziegelbauer J, Williams $\mathrm{CB}$. Affinity-based selection of regulatory $\mathrm{T}$ cells occurs independent of agonist-mediated induction of Foxp3 expression. J Immunol (2009) 182 (3):1341-50. doi: 10.4049/jimmunol.182.3.1341

49. Relland LM, Williams JB, Relland GN, Haribhai D, Ziegelbauer J, Yassai M, et al. The TCR repertoires of regulatory and conventional T cells specific for the same foreign antigen are distinct. J Immunol (2012) 189(7):3566-74. doi: 10.4049/jimmunol.1102646

50. Wong J, Obst R, Correia-Neves M, Losyev G, Mathis D, Benoist C. Adaptation of TCR repertoires to self-peptides in regulatory and nonregulatory CD4+ T cells. J Immunol (2007) 178(11):7032-41. doi: 10.4049/jimmunol.178.11.7032

51. Hsieh CS, Zheng Y, Liang Y, Fontenot JD, Rudensky AY. An intersection between the self-reactive regulatory and nonregulatory $\mathrm{T}$ cell receptor repertoires. Nat Immunol (2006) 7(4):401-10. doi: 10.1038/ni1318

52. Shevach EM, Thornton AM. tTregs, pTregs, and iTregs: similarities and differences. Immunol Rev (2014) 259(1):88-102. doi: 10.1111/imr.12160

53. Corbel C, Lemarchandel V, Thomas-Vaslin V, Pelus AS, Agboton C, Romeo $\mathrm{PH}$. Neuropilin 1 and $\mathrm{CD} 25$ co-regulation during early murine thymic differentiation. Dev Comp Immunol (2007) 31(11):1082-94. doi: 10.1016/ j.dci.2007.01.009

54. Akimova T, Beier UH, Wang L, Levine MH, Hancock WW. Helios expression is a marker of $\mathrm{T}$ cell activation and proliferation. PloS One (2011) 6(8):e24226. doi: 10.1371/journal.pone.0024226

55. Gottschalk RA, Corse E, Allison JP. Expression of Helios in peripherally induced Foxp3+ regulatory T cells. J Immunol (2012) 188(3):976-80. doi: 10.4049/jimmunol.1102964

56. Schliesser U, Chopra M, Beilhack A, Appelt C, Vogel S, Schumann J, et al. Generation of highly effective and stable murine alloreactive Treg cells by combined anti-CD4 mAb, TGF-beta, and RA treatment. Eur J Immunol (2013) 43(12):3291-305. doi: 10.1002/eji.201243292

57. Satou Y, Utsunomiya A, Tanabe J, Nakagawa M, Nosaka K, Matsuoka M. HTLV-1 modulates the frequency and phenotype of FoxP3+CD4+ T cells in virus-infected individuals. Retrovirology (2012) 9:46. doi: 10.1186/17424690-9-46

58. Szurek E, Cebula A, Wojciech L, Pietrzak M, Rempala G, Kisielow P, et al. Differences in Expression Level of Helios and Neuropilin-1 Do Not Distinguish Thymus-Derived from Extrathymically-Induced CD4+Foxp3+ Regulatory T Cells. PloS One (2015) 10(10):e0141161. doi: 10.1371/ journal.pone. 0141161

59. Kim YC, Bhairavabhotla R, Yoon J, Golding A, Thornton AM, Tran DQ, et al. Oligodeoxynucleotides stabilize Helios-expressing Foxp3+ human T regulatory cells during in vitro expansion. Blood (2012) 119(12):2810-8. doi: 10.1182/blood-2011-09-377895

60. Yadav M, Louvet C, Davini D, Gardner JM, Martinez-Llordella M, BaileyBucktrout $\mathrm{S}$, et al. Neuropilin-1 distinguishes natural and inducible regulatory $\mathrm{T}$ cells among regulatory $\mathrm{T}$ cell subsets in vivo. J Exp Med (2012) 209(10):1713-22, S1-19. doi: 10.1084/jem.20120822

61. Nowatzky J, Stagnar C, Manches O. OMIP-053: Identification, Classification, and Isolation of Major FoxP3 Expressing Human CD4(+) Treg Subsets. Cytometry A (2019) 95(3):264-7. doi: 10.1002/cyto.a.23704

62. Santegoets SJ, Dijkgraaf EM, Battaglia A, Beckhove P, Britten CM, Gallimore A, et al. Monitoring regulatory $\mathrm{T}$ cells in clinical samples: consensus on an essential marker set and gating strategy for regulatory $\mathrm{T}$ cell analysis by flow cytometry. Cancer Immunol Immunother (2015) 64(10):1271-86. doi: $10.1007 / \mathrm{s} 00262-015-1729-\mathrm{x}$

63. Lam EW, Brosens JJ, Gomes AR, Koo CY. Forkhead box proteins: tuning forks for transcriptional harmony. Nat Rev Cancer (2013) 13(7):482-95. doi: $10.1038 / \mathrm{nrc} 3539$

64. Jackson BC, Carpenter C, Nebert DW, Vasiliou V. Update of human and mouse forkhead box (FOX) gene families. Hum Genomics (2010) 4(5):34552. doi: 10.1186/1479-7364-4-5-345

65. Ichiyama K, Yoshida H, Wakabayashi $Y$, Chinen T, Saeki K, Nakaya M, et al. Foxp3 inhibits RORgammat-mediated IL-17A mRNA transcription through direct interaction with RORgammat. J Biol Chem (2008) 283(25):17003-8. doi: $10.1074 /$ jbc.M801286200

66. Mailer RKW. Alternative Splicing of FOXP3-Virtue and Vice. Front Immunol (2018) 9:530:530. doi: 10.3389/fimmu.2018.00530

67. Deng G, Song X, Greene MI. FoxP3 in Treg cell biology: a molecular and structural perspective. Clin Exp Immunol (2020) 199(3):255-62. doi: $10.1111 /$ cei.13357

68. Bettelli E, Dastrange M, Oukka M. Foxp3 interacts with nuclear factor of activated T cells and NF-kappa B to repress cytokine gene expression and effector functions of T helper cells. Proc Natl Acad Sci USA (2005) 102 (14):5138-43. doi: 10.1073/pnas.0501675102

69. Li B, Samanta A, Song X, Iacono KT, Brennan P, Chatila TA, et al. FOXP3 is a homo-oligomer and a component of a supramolecular regulatory complex disabled in the human XLAAD/IPEX autoimmune disease. Int Immunol (2007) 19(7):825-35. doi: 10.1093/intimm/dxm043

70. Chae WJ, Henegariu O, Lee SK, Bothwell AL. The mutant leucine-zipper domain impairs both dimerization and suppressive function of Foxp3 in T cells. Proc Natl Acad Sci USA (2006) 103(25):9631-6. doi: 10.1073/ pnas. 0600225103

71. Lopes JE, Torgerson TR, Schubert LA, Anover SD, Ocheltree EL, Ochs HD, et al. Analysis of FOXP3 reveals multiple domains required for its function as a transcriptional repressor. J Immunol (2006) 177(5):3133-42. doi: 10.4049/jimmunol.177.5.3133

72. Lalmansingh AS, Karmakar S, Jin Y, Nagaich AK. Multiple modes of chromatin remodeling by Forkhead box proteins. Biochim Biophys Acta (2012) 1819(7):707-15. doi: 10.1016/j.bbagrm.2012.02.018

73. Li J, Jiang L, Liang X, Qu L, Wu D, Chen X, et al. DNA-binding properties of FOXP3 transcription factor. Acta Biochim Biophys Sin (Shanghai) (2017) 49 (9):792-9. doi: 10.1093/abbs/gmx079

74. Samstein RM, Arvey A, Josefowicz SZ, Peng X, Reynolds A, Sandstrom R, et al. Foxp3 exploits a pre-existent enhancer landscape for regulatory $\mathrm{T}$ cell lineage specification. Cell (2012) 151(1):153-66. doi: 10.1016/ j.cell.2012.06.053

75. Rudra D, deRoos P, Chaudhry A, Niec RE, Arvey A, Samstein RM, et al. Transcription factor Foxp3 and its protein partners form a complex regulatory network. Nat Immunol (2012) 13(10):1010-9. doi: 10.1038/ ni. 2402

76. Huang J, Wang S, Jia Y, Zhang Y, Dai X, Li B. Targeting FOXP3 complex ensemble in drug discovery. Adv Protein Chem Struct Biol (2020) 121:14368. doi: 10.1016/bs.apcsb.2019.11.010

77. Wu Y, Borde M, Heissmeyer V, Feuerer M, Lapan AD, Stroud JC, et al. FOXP3 controls regulatory $\mathrm{T}$ cell function through cooperation with NFAT. Cell (2006) 126(2):375-87. doi: 10.1016/j.cell.2006.05.042

78. Ono M, Yaguchi H, Ohkura N, Kitabayashi I, Nagamura Y, Nomura T, et al. Foxp3 controls regulatory T-cell function by interacting with AML1/Runx1. Nature (2007) 446(7136):685-9. doi: 10.1038/nature05673

79. Du J, Huang C, Zhou B, Ziegler SF. Isoform-specific inhibition of ROR alpha-mediated transcriptional activation by human FOXP3. J Immunol (2008) 180(7):4785-92. doi: 10.4049/jimmunol.180.7.4785

80. Ruan Q, Kameswaran V, Tone Y, Li L, Liou HC, Greene MI, et al. Development of Foxp3(+) regulatory $\mathrm{t}$ cells is driven by the $\mathrm{c}$-Rel enhanceosome. Immunity (2009) 31(6):932-40. doi: 10.1016/ j.immuni.2009.10.006

81. Zheng Y, Chaudhry A, Kas A, deRoos P, Kim JM, Chu TT, et al. Regulatory T-cell suppressor program co-opts transcription factor IRF4 to control $\mathrm{T}(\mathrm{H})$ 2 responses. Nature (2009) 458(7236):351-6. doi: 10.1038/nature07674

82. Pan F, Yu H, Dang EV, Barbi J, Pan X, Grosso JF, et al. Eos mediates Foxp3dependent gene silencing in CD4+ regulatory T cells. Science (2009) 325 (5944):1142-6. doi: 10.1126/science.1176077

83. Chaudhry A, Rudra D, Treuting P, Samstein RM, Liang Y, Kas A, et al. CD4+ regulatory T cells control TH17 responses in a Stat3-dependent manner. Science (2009) 326(5955):986-91. doi: 10.1126/science.1172702

84. Dang EV, Barbi J, Yang HY, Jinasena D, Yu H, Zheng Y, et al. Control of T (H)17/T(reg) balance by hypoxia-inducible factor 1. Cell (2011) 146(5):77284. doi: 10.1016/j.cell.2011.07.033

85. Huang C, Martin S, Pfleger C, Du J, Buckner JH, Bluestone JA, et al. Cutting Edge: a novel, human-specific interacting protein couples FOXP3 to a 
chromatin-remodeling complex that contains KAP1/TRIM28. J Immunol (2013) 190(9):4470-3. doi: 10.4049/jimmunol.1203561

86. DuPage M, Chopra G, Quiros J, Rosenthal WL, Morar MM, Holohan D, et al. The chromatin-modifying enzyme Ezh2 is critical for the maintenance of regulatory T cell identity after activation. Immunity (2015) 42(2):227-38. doi: 10.1016/j.immuni.2015.01.007

87. Kwon HK, Chen HM, Mathis D, Benoist C. Different molecular complexes that mediate transcriptional induction and repression by FoxP3. Nat Immunol (2017) 18(11):1238-48. doi: 10.1038/ni.3835

88. Portela A, Esteller M. Epigenetic modifications and human disease. Nat Biotechnol (2010) 28(10):1057-68. doi: 10.1038/nbt.1685

89. Colamatteo A, Carbone F, Bruzzaniti S, Galgani M, Fusco C, Maniscalco GT, et al. Molecular Mechanisms Controlling Foxp3 Expression in Health and Autoimmunity: From Epigenetic to Post-translational Regulation. Front Immunol (2019) 10:3136. doi: 10.3389/fimmu.2019.03136

90. Cortez JT, Montauti E, Shifrut E, Gatchalian J, Zhang Y, Shaked O, et al. CRISPR screen in regulatory $\mathrm{T}$ cells reveals modulators of Foxp3. Nature (2020) 582(7812):416-20. doi: 10.1038/s41586-020-2246-4

91. Rouas R, Fayyad-Kazan H, El Zein N, Lewalle P, Rothe F, Simion A, et al. Human natural Treg microRNA signature: role of microRNA-31 and microRNA-21 in FOXP3 expression. Eur J Immunol (2009) 39(6):160818. doi: 10.1002/eji.200838509

92. Fayyad-Kazan H, Rouas R, Fayyad-Kazan M, Badran R, El Zein N, Lewalle P, et al. MicroRNA profile of circulating CD4-positive regulatory $\mathrm{T}$ cells in human adults and impact of differentially expressed microRNAs on expression of two genes essential to their function. J Biol Chem (2012) 287 (13):9910-22. doi: 10.1074/jbc.M111.337154

93. Zheng Y, Josefowicz S, Chaudhry A, Peng XP, Forbush K, Rudensky AY. Role of conserved non-coding DNA elements in the Foxp3 gene in regulatory T-cell fate. Nature (2010) 463(7282):808-12. doi: 10.1038/ nature 08750

94. Placek K, Hu G, Cui K, Zhang D, Ding Y, Lee JE, et al. MLL4 prepares the enhancer landscape for Foxp3 induction via chromatin looping. Nat Immunol (2017) 18(9):1035-45. doi: 10.1038/ni.3812

95. Gupta S, Manicassamy S, Vasu C, Kumar A, Shang W, Sun Z. Differential requirement of $\mathrm{PKC}$-theta in the development and function of natural regulatory T cells. Mol Immunol (2008) 46(2):213-24. doi: 10.1016/ j.molimm.2008.08.275

96. Schmidt-Supprian M, Tian J, Grant EP, Pasparakis M, Maehr R, Ovaa H, et al. Differential dependence of CD4+CD25+ regulatory and natural killerlike T cells on signals leading to NF-kappaB activation. Proc Natl Acad Sci USA (2004) 101(13):4566-71. doi: 10.1073/pnas.0400885101

97. Barnes MJ, Krebs P, Harris N, Eidenschenk C, Gonzalez-Quintial R, Arnold $\mathrm{CN}$, et al. Commitment to the regulatory $\mathrm{T}$ cell lineage requires CARMA1 in the thymus but not in the periphery. PloS Biol (2009) 7(3):e51. doi: 10.1371/ journal.pbio. 1000051

98. Molinero LL, Yang J, Gajewski T, Abraham C, Farrar MA, Alegre ML. CARMA1 controls an early checkpoint in the thymic development of FoxP3 + regulatory T cells. J Immunol (2009) 182(11):6736-43. doi: 10.4049/ jimmunol.0900498

99. Schmidt-Supprian M, Courtois G, Tian J, Coyle AJ, Israel A, Rajewsky K, et al. Mature $\mathrm{T}$ cells depend on signaling through the IKK complex. Immunity (2003) 19(3):377-89. doi: 10.1016/s1074-7613(03)00237-1

100. Deenick EK, Elford AR, Pellegrini M, Hall H, Mak TW, Ohashi PS. c-Rel but not NF-kappaB1 is important for T regulatory cell development. Eur J Immunol (2010) 40(3):677-81. doi: 10.1002/eji.201040298

101. Isomura I, Palmer S, Grumont RJ, Bunting K, Hoyne G, Wilkinson N, et al. c-Rel is required for the development of thymic Foxp3+ CD4 regulatory T cells. J Exp Med (2009) 206(13):3001-14. doi: 10.1084/ jem.20091411

102. Grigoriadis G, Vasanthakumar A, Banerjee A, Grumont R, Overall S, Gleeson P, et al. c-Rel controls multiple discrete steps in the thymic development of Foxp3+ CD4 regulatory T cells. PloS One (2011) 6(10): e26851. doi: 10.1371/journal.pone.0026851

103. Long M, Park SG, Strickland I, Hayden MS, Ghosh S. Nuclear factor-kappaB modulates regulatory $\mathrm{T}$ cell development by directly regulating expression of Foxp3 transcription factor. Immunity (2009) 31(6):921-31. doi: 10.1016/ j.immuni.2009.09.022
104. Wang H, Zhao L, Sun Z, Sun L, Zhang B, Zhao Y. A potential side effect of cyclosporin A: inhibition of $\mathrm{CD} 4(+) \mathrm{CD} 25(+)$ regulatory $\mathrm{T}$ cells in mice. Transplantation (2006) 82(11):1484-92. doi: 10.1097/01.tp.0000246312. 89689.17

105. Tone Y, Furuuchi K, Kojima Y, Tykocinski ML, Greene MI, Tone M. Smad3 and NFAT cooperate to induce Foxp3 expression through its enhancer. Nat Immunol (2008) 9(2):194-202. doi: 10.1038/ni1549

106. Macian F. NFAT proteins: key regulators of T-cell development and function. Nat Rev Immunol (2005) 5(6):472-84. doi: 10.1038/nri1632

107. Mantel PY, Ouaked N, Ruckert B, Karagiannidis C, Welz R, Blaser K, et al. Molecular mechanisms underlying FOXP3 induction in human $\mathrm{T}$ cells. J Immunol (2006) 176(6):3593-602. doi: 10.4049/jimmunol.176.6.3593

108. D'Cruz LM, Klein L. Development and function of agonist-induced CD25 +Foxp3+ regulatory T cells in the absence of interleukin 2 signaling. Nat Immunol (2005) 6(11):1152-9. doi: 10.1038/ni1264

109. Fontenot JD, Rasmussen JP, Gavin MA, Rudensky AY. A function for interleukin 2 in Foxp3-expressing regulatory T cells. Nat Immunol (2005) 6(11):1142-51. doi: 10.1038/ni1263

110. Burchill MA, Yang J, Vogtenhuber C, Blazar BR, Farrar MA. IL-2 receptor betadependent STAT5 activation is required for the development of Foxp3+ regulatory T cells. J Immunol (2007) 178(1):280-90. doi: 10.4049/jimmunol.178.1.280

111. Chinen T, Kannan AK, Levine AG, Fan X, Klein U, Zheng Y, et al. An essential role for the IL-2 receptor in Treg cell function. Nat Immunol (2016) 17(11):1322-33. doi: 10.1038/ni.3540

112. Toomer KH, Lui JB, Altman NH, Ban Y, Chen X, Malek TR. Essential and non-overlapping IL-2Ralpha-dependent processes for thymic development and peripheral homeostasis of regulatory T cells. Nat Commun (2019) 10 (1):1037. doi: 10.1038/s41467-019-08960-1

113. Imada K, Leonard WJ. The Jak-STAT pathway. Mol Immunol (2000) 37(12):1-11. doi: 10.1016/s0161-5890(00)00018-3

114. Yao Z, Kanno Y, Kerenyi M, Stephens G, Durant L, Watford WT, et al. Nonredundant roles for Stat5a/b in directly regulating Foxp3. Blood (2007) 109(10):4368-75. doi: 10.1182/blood-2006-11-055756

115. Wang J, Wicker LS, Santamaria P. IL-2 and its high-affinity receptor: genetic control of immunoregulation and autoimmunity. Semin Immunol (2009) 21 (6):363-71. doi: 10.1016/j.smim.2009.04.004

116. Ye C, Brand D, Zheng SG. Targeting IL-2: an unexpected effect in treating immunological diseases. Signal Transduct Targ Ther (2018) 3:2. doi: 10.1038/ s41392-017-0002-5

117. Takimoto T, Wakabayashi Y, Sekiya T, Inoue N, Morita R, Ichiyama K, et al. Smad2 and Smad3 are redundantly essential for the TGF-beta-mediated regulation of regulatory T plasticity and Th1 development. J Immunol (2010) 185(2):842-55. doi: 10.4049/jimmunol.0904100

118. Samon JB, Champhekar A, Minter LM, Telfer JC, Miele L, Fauq A, et al. Notch1 and TGFbetal cooperatively regulate Foxp3 expression and the maintenance of peripheral regulatory T cells. Blood (2008) 112(5):1813-21. doi: 10.1182/blood-2008-03-144980

119. Deng G, Song X, Fujimoto S, Piccirillo CA, Nagai Y, Greene MI. Foxp3 Posttranslational Modifications and Treg Suppressive Activity. Front Immunol (2019) 10:2486. doi: 10.3389/fimmu.2019.02486

120. Chunder N, Wang L, Chen C, Hancock WW, Wells AD. Cyclin-dependent kinase 2 controls peripheral immune tolerance. J Immunol (2012) 189 (12):5659-66. doi: 10.4049/jimmunol.1202313

121. Morawski PA, Mehra P, Chen C, Bhatti T, Wells AD. Foxp3 protein stability is regulated by cyclin-dependent kinase 2. J Biol Chem (2013) 288 (34):24494-502. doi: 10.1074/jbc.M113.467704

122. Li Z, Lin F, Zhuo C, Deng G, Chen Z, Yin S, et al. PIM1 kinase phosphorylates the human transcription factor FOXP3 at serine 422 to negatively regulate its activity under inflammation. J Biol Chem (2014) 289 (39):26872-81. doi: 10.1074/jbc.M114.586651

123. Deng G, Nagai Y, Xiao Y, Li Z, Dai S, Ohtani T, et al. Pim-2 Kinase Influences Regulatory $\mathrm{T}$ Cell Function and Stability by Mediating Foxp3 Protein N-terminal Phosphorylation. J Biol Chem (2015) 290(33):20211-20. doi: 10.1074/jbc.M115.638221

124. Basu S, Golovina T, Mikheeva T, June CH, Riley JL. Cutting edge: Foxp3mediated induction of pim 2 allows human $\mathrm{T}$ regulatory cells to preferentially expand in rapamycin. J Immunol (2008) 180(9):5794-8. doi: 10.4049/jimmunol.180.9.5794 
125. Gavin MA, Torgerson TR, Houston E, DeRoos P, Ho WY, Stray-Pedersen A, et al. Single-cell analysis of normal and FOXP3-mutant human T cells: FOXP3 expression without regulatory T cell development. Proc Natl Acad Sci U S A (2006) 103(17):6659-64. doi: 10.1073/pnas.0509484103

126. Fleskens V, Minutti CM, Wu X, Wei P, Pals C, McCrae J, et al. Nemo-like Kinase Drives Foxp3 Stability and Is Critical for Maintenance of Immune Tolerance by Regulatory T Cells. Cell Rep (2019) 26(13):3600-12.e6. doi: 10.1016/j.celrep.2019.02.087

127. Nie H, Zheng Y, Li R, Guo TB, He D, Fang L, et al. Phosphorylation of FOXP3 controls regulatory $\mathrm{T}$ cell function and is inhibited by TNFalpha in rheumatoid arthritis. Nat Med (2013) 19(3):322-8. doi: 10. 1038/nm.3085

128. Xiao Y, Li B, Zhou Z, Hancock WW, Zhang H, Greene MI. Histone acetyltransferase mediated regulation of FOXP3 acetylation and Treg function. Curr Opin Immunol (2010) 22(5):583-91. doi: 10.1016/ j.coi.2010.08.013

129. Liu Y, Wang L, Han R, Beier UH, Akimova T, Bhatti T, et al. Two histone/ protein acetyltransferases, CBP and p300, are indispensable for Foxp3+ Tregulatory cell development and function. Mol Cell Biol (2014) 34(21):39934007. doi: 10.1128/MCB.00919-14

130. Kwon HS, Lim HW, Wu J, Schnolzer M, Verdin E, Ott M. Three novel acetylation sites in the Foxp3 transcription factor regulate the suppressive activity of regulatory T cells. J Immunol (2012) 188(6):2712-21. doi: 10.4049/ jimmunol.1100903

131. Li B, Samanta A, Song X, Iacono KT, Bembas K, Tao R, et al. FOXP3 interactions with histone acetyltransferase and class II histone deacetylases are required for repression. Proc Natl Acad Sci U S A (2007) 104(11):4571-6. doi: 10.1073/pnas.0700298104

132. Xiao Y, Nagai Y, Deng G, Ohtani T, Zhu Z, Zhou Z, et al. Dynamic interactions between TIP60 and p300 regulate FOXP3 function through a structural switch defined by a single lysine on TIP60. Cell Rep (2014) 7 (5):1471-80. doi: 10.1016/j.celrep.2014.04.021

133. Du T, Nagai Y, Xiao Y, Greene MI, Zhang H. Lysosome-dependent p300/ FOXP3 degradation and limits Treg cell functions and enhances targeted therapy against cancers. Exp Mol Pathol (2013) 95(1):38-45. doi: 10.1016/ j.yexmp.2013.04.003

134. Bin Dhuban K, d'Hennezel E, Nagai Y, Xiao Y, Shao S, Istomine R, et al. Suppression by human FOXP3(+) regulatory T cells requires FOXP3-TIP60 interactions. Sci Immunol (2017) 2(12):eaai9297. doi: 10.1126/ sciimmunol.aai9297

135. Song X, Li B, Xiao Y, Chen C, Wang Q, Liu Y, et al. Structural and biological features of FOXP3 dimerization relevant to regulatory $\mathrm{T}$ cell function. Cell Rep (2012) 1(6):665-75. doi: 10.1016/j.celrep.2012.04.012

136. Tao R, de Zoeten EF, Ozkaynak E, Chen C, Wang L, Porrett PM, et al. Deacetylase inhibition promotes the generation and function of regulatory $\mathrm{T}$ cells. Nat Med (2007) 13(11):1299-307. doi: 10.1038/nm1652

137. Samanta A, Li B, Song X, Bembas K, Zhang G, Katsumata M, et al. TGF-beta and IL- 6 signals modulate chromatin binding and promoter occupancy by acetylated FOXP3. Proc Natl Acad Sci U S A (2008) 105(37):14023-7. doi: $10.1073 /$ pnas. 0806726105

138. Wang L, Liu Y, Han R, Beier UH, Bhatti TR, Akimova T, et al. FOXP3(+) regulatory $\mathrm{T}$ cell development and function require histone/protein deacetylase 3. J Clin Invest (2015) 125(8):3304. doi: 10.1172/JCI83084

139. de Zoeten EF, Wang L, Butler K, Beier UH, Akimova T, Sai H, et al. Histone deacetylase 6 and heat shock protein 90 control the functions of Foxp3(+) Tregulatory cells. Mol Cell Biol (2011) 31(10):2066-78. doi: 10.1128/ MCB.05155-11

140. Sadlon TJ, Wilkinson BG, Pederson S, Brown CY, Bresatz S, Gargett T, et al. Genome-wide identification of human FOXP3 target genes in natural regulatory T cells. J Immunol (2010) 185(2):1071-81. doi: 10.4049/ jimmunol.1000082

141. Tao R, Hancock WW. Resistance of Foxp3+ regulatory T cells to Nur77induced apoptosis promotes allograft survival. PloS One (2008) 3(5):e2321. doi: 10.1371/journal.pone.0002321

142. Beier UH, Wang L, Han R, Akimova T, Liu Y, Hancock WW. Histone deacetylases 6 and 9 and sirtuin- 1 control Foxp3+ regulatory T cell function through shared and isoform-specific mechanisms. Sci Signal (2012) 5(229): ra45. doi: 10.1126/scisignal.2002873
143. Dahiya S, Beier UH, Wang L, Han R, Jiao J, Akimova T, et al. HDAC10 deletion promotes Foxp3(+) T-regulatory cell function. Sci Rep (2020) 10 (1):424. doi: 10.1038/s41598-019-57294-x

144. Wang J, Chen J. SIRT1 regulates autoacetylation and histone acetyltransferase activity of TIP60. J Biol Chem (2010) 285(15):11458-64. doi: 10.1074/jbc.M109.087585

145. Beier UH, Wang L, Bhatti TR, Liu Y, Han R, Ge G, et al. Sirtuin-1 targeting promotes Foxp3+ T-regulatory cell function and prolongs allograft survival. Mol Cell Biol (2011) 31(5):1022-9. doi: 10.1128/MCB.01206-10

146. Huang J, Wang L, Dahiya S, Beier UH, Han R, Samanta A, et al. Histone/ protein deacetylase 11 targeting promotes Foxp3+ Treg function. Sci Rep (2017) 7(1):8626. doi: 10.1038/s41598-017-09211-3

147. Schubert HL, Blumenthal RM, Cheng X. 1 Protein Methyltransferases: Their Distribution Among the Five Structural Classes of AdoMetDependent Methyltransferases. Enzymes (2006) 24:3-28. doi: 10.1016/S1874-6047 (06)80003-X

148. Kagoya Y, Saijo H, Matsunaga Y, Guo T, Saso K, Anczurowski M, et al. Arginine methylation of FOXP3 is crucial for the suppressive function of regulatory T cells. J Autoimmun (2019) 97:10-21. doi: 10.1016/ j.jaut.2018.09.011

149. Sen S, He Z, Ghosh S, Dery KJ, Yang L, Zhang J, et al. PRMT1 Plays a Critical Role in Th17 Differentiation by Regulating Reciprocal Recruitment of STAT3 and STAT5. J Immunol (2018) 201(2):440-50. doi: 10.4049/ jimmunol.1701654

150. Nagai Y, Ji MQ, Zhu F, Xiao Y, Tanaka Y, Kambayashi T, et al. PRMT5 Associates With the FOXP3 Homomer and When Disabled Enhances Targeted p185(erbB2/neu) Tumor Immunotherapy. Front Immunol (2019) 10:174. doi: 10.3389/fimmu.2019.00174

151. Tanaka Y, Nagai Y, Okumura M, Greene MI, Kambayashi T. PRMT5 Is Required for T Cell Survival and Proliferation by Maintaining Cytokine Signaling. Front Immunol (2020) 11:621. doi: 10.3389/fimmu.2020.00621

152. Webb LM, Sengupta S, Edell C, Piedra-Quintero ZL, Amici SA, Miranda JN, et al. Protein arginine methyltransferase 5 promotes cholesterol biosynthesismediated Th17 responses and autoimmunity. J Clin Invest (2020) 130 (4):1683-98. doi: 10.1172/JCI131254

153. Chang YH, Weng CL, Lin KI. O-GlcNAcylation and its role in the immune system. J BioMed Sci (2020) 27(1):57. doi: 10.1186/s12929-020-00648-9

154. Cabral J, Hanley SA, Gerlach JQ, O’Leary N, Cunningham S, Ritter T, et al. Distinctive Surface Glycosylation Patterns Associated With Mouse and Human CD4(+) Regulatory T Cells and Their Suppressive Function. Front Immunol (2017) 8:987. doi: 10.3389/fimmu.2017.00987

155. Jimenez-Martinez MC, Lascurain R, Mendez-Reguera A, Estrada-Parra S, Estrada-Garcia I, Gorocica P, et al. O-glycosylation of NnTreg lymphocytes recognized by the Amaranthus leucocarpus lectin. Clin Dev Immunol (2013) 2013:506807. doi: 10.1155/2013/506807

156. Liu B, Salgado OC, Singh S, Hippen KL, Maynard JC, Burlingame AL, et al. The lineage stability and suppressive program of regulatory $\mathrm{T}$ cells require protein O-GlcNAcylation. Nat Commun (2019) 10(1):354. doi: 10.1038/ s41467-019-08300-3

157. Hao X, Li Y, Wang J, Ma J, Zhao S, Ye X, et al. Deficient O-GlcNAc Glycosylation Impairs Regulatory T Cell Differentiation and Notch Signaling in Autoimmune Hepatitis. Front Immunol (2018) 9:2089. doi: 10.3389/ fimmu.2018.02089

158. Ramakrishnan P, Clark PM, Mason DE, Peters EC, Hsieh-Wilson LC, Baltimore D. Activation of the transcriptional function of the NF-kappaB protein c-Rel by O-GlcNAc glycosylation. Sci Signal (2013) 6(290):ra75. doi: 10.1126/scisignal.2004097

159. de Jesus TJ, Ramakrishnan P. NF-kappaB c-Rel Dictates the Inflammatory Threshold by Acting as a Transcriptional Repressor. iScience (2020) 23 (3):100876. doi: 10.1016/j.isci.2020.100876

160. Ciehanover A, Hod Y, Hershko A. A heat-stable polypeptide component of an ATP-dependent proteolytic system from reticulocytes. Biochem Biophys Res Commun (1978) 81(4):1100-5. doi: 10.1016/0006-291X(78)91249-4

161. Komander D, Rape M. The ubiquitin code. Annu Rev Biochem (2012) 81:203-29. doi: 10.1146/annurev-biochem-060310-170328

162. Nijman SM, Luna-Vargas MP, Velds A, Brummelkamp TR, Dirac AM, Sixma TK, et al. A genomic and functional inventory of deubiquitinating enzymes. Cell (2005) 123(5):773-86. doi: 10.1016/j.cell.2005.11.007 
163. Stieglitz B, Morris-Davies AC, Koliopoulos MG, Christodoulou E, Rittinger K. LUBAC synthesizes linear ubiquitin chains via a thioester intermediate. EMBO Rep (2012) 13(9):840-6. doi: 10.1038/embor.2012.105

164. Kirisako T, Kamei K, Murata S, Kato M, Fukumoto H, Kanie M, et al. A ubiquitin ligase complex assembles linear polyubiquitin chains. EMBO J (2006) 25(20):4877-87. doi: 10.1038/sj.emboj.7601360

165. Redecke V, Chaturvedi V, Kuriakose J, Hacker H. SHARPIN controls the development of regulatory T cells. Immunology (2016) 148(2):216-26. doi: $10.1111 / \mathrm{imm} .12604$

166. Gerlach B, Cordier SM, Schmukle AC, Emmerich CH, Rieser E, Haas TL, et al. Linear ubiquitination prevents inflammation and regulates immune signalling. Nature (2011) 471(7340):591-6. doi: 10.1038/nature09816

167. Zinngrebe J, Rieser E, Taraborrelli L, Peltzer N, Hartwig T, Ren H, et al. -LUBAC deficiency perturbs TLR3 signaling to cause immunodeficiency and autoinflammation. JExp Med (2016) 213(12):2671-89. doi: 10.1084/jem.20160041

168. Damgaard RB, Nachbur U, Yabal M, Wong WW, Fiil BK, Kastirr M, et al. The ubiquitin ligase XIAP recruits LUBAC for NOD2 signaling in inflammation and innate immunity. Mol Cell (2012) 46(6):746-58. doi: 10.1016/j.molcel.2012.04.014

169. Rodgers MA, Bowman JW, Fujita H, Orazio N, Shi M, Liang Q, et al. The linear ubiquitin assembly complex (LUBAC) is essential for NLRP3 inflammasome activation. J Exp Med (2014) 211(7):1333-47. doi: 10.1084/ jem.20132486

170. Sasaki Y, Sano S, Nakahara M, Murata S, Kometani K, Aiba Y, et al. Defective immune responses in mice lacking LUBAC-mediated linear ubiquitination in B cells. EMBO J (2013) 32(18):2463-76. doi: 10.1038/emboj.2013.184

171. Haas TL, Emmerich CH, Gerlach B, Schmukle AC, Cordier SM, Rieser E, et al. Recruitment of the linear ubiquitin chain assembly complex stabilizes the TNF-R1 signaling complex and is required for TNF-mediated gene induction. Mol Cell (2009) 36(5):831-44. doi: 10.1016/j.molcel.2009.10.013

172. Park Y, Jin HS, Lopez J, Lee J, Liao L, Elly C, et al. SHARPIN controls regulatory $\mathrm{T}$ cells by negatively modulating the $\mathrm{T}$ cell antigen receptor complex. Nat Immunol (2016) 17(3):286-96. doi: 10.1038/ni.3352

173. Zhu F, Yi G, Liu X, Zhu F, Zhao A, Wang A, et al. Ring finger protein 31mediated atypical ubiquitination stabilizes forkhead box P3 and thereby stimulates regulatory T-cell function. J Biol Chem (2018) 293(52):20099-111. doi: 10.1074/jbc.RA118.005802

174. Teh CE, Lalaoui N, Jain R, Policheni AN, Heinlein M, Alvarez-Diaz S, et al. Linear ubiquitin chain assembly complex coordinates late thymic T-cell differentiation and regulatory T-cell homeostasis. Nat Commun (2016) 7:13353. doi: $10.1038 /$ ncomms 13353

175. Ballinger CA, Connell $\mathrm{P}, \mathrm{Wu} \mathrm{Y,} \mathrm{Hu} \mathrm{Z,} \mathrm{Thompson} \mathrm{LJ,} \mathrm{Yin} \mathrm{LY,} \mathrm{et} \mathrm{al.}$ Identification of CHIP, a novel tetratricopeptide repeat-containing protein that interacts with heat shock proteins and negatively regulates chaperone functions. Mol Cell Biol (1999) 19(6):4535-45. doi: 10.1128/MCB.19.6.4535

176. Chen Z, Barbi J, Bu S, Yang HY, Li Z, Gao Y, et al. The ubiquitin ligase Stub1 negatively modulates regulatory $\mathrm{T}$ cell suppressive activity by promoting degradation of the transcription factor Foxp3. Immunity (2013) 39(2):27285. doi: 10.1016/j.immuni.2013.08.006

177. Wang S, Li Y, Hu YH, Song R, Gao Y, Liu HY, et al. STUB1 is essential for Tcell activation by ubiquitinating CARMA1. Eur J Immunol (2013) 43 (4):1034-41. doi: 10.1002/eji.201242554

178. Kobayashi T, Walsh PT, Walsh MC, Speirs KM, Chiffoleau E, King CG, et al. TRAF6 is a critical factor for dendritic cell maturation and development. Immunity (2003) 19(3):353-63. doi: 10.1016/S1074-7613(03)00230-9

179. Ni X, Kou W, Gu J, Wei P, Wu X, Peng H, et al. TRAF6 directs FOXP3 localization and facilitates regulatory T-cell function through K63-linked ubiquitination. EMBO J (2019) 38(9):e99766. doi: 10.15252/embj.201899766

180. van Loosdregt J, Fleskens V, Fu J, Brenkman AB, Bekker CP, Pals CE, et al. Stabilization of the transcription factor Foxp3 by the deubiquitinase USP7 increases Treg-cell-suppressive capacity. Immunity (2013) 39(2):259-71. doi: 10.1016/j.immuni.2013.05.018

181. Wang L, Kumar S, Dahiya S, Wang F, Wu J, Newick K, et al. Ubiquitinspecific Protease-7 Inhibition Impairs Tip60-dependent Foxp3+ Tregulatory Cell Function and Promotes Antitumor Immunity. EBioMedicine (2016) 13:99-112. doi: 10.1016/j.ebiom.2016.10.018

182. Li Y, Lu Y, Wang S, Han Z, Zhu F, Ni Y, et al. USP21 prevents the generation of Thelper-1-like Treg cells. Nat Commun (2016) 7:13559. doi: 10.1038/ncomms13559
183. Zhang J, Chen C, Hou X, Gao Y, Lin F, Yang J, et al. Identification of the E3 deubiquitinase ubiquitin-specific peptidase 21 (USP21) as a positive regulator of the transcription factor GATA3. J Biol Chem (2013) 288 (13):9373-82. doi: 10.1074/jbc.M112.374744

184. Pannu J, Belle JI, Forster M, Duerr CU, Shen S, Kane L, et al. Ubiquitin specific protease 21 is dispensable for normal development, hematopoiesis and lymphocyte differentiation. PloS One (2015) 10(2):e0117304. doi: 10.1371/journal.pone.0117304

185. Yang J, Wei P, Barbi J, Huang Q, Yang E, Bai Y, et al. The deubiquitinase USP44 promotes Treg function during inflammation by preventing FOXP3 degradation. EMBO Rep (2020) 21(9):e50308. doi: 10.15252/embr.202050308

186. Lozano T, Villanueva L, Durantez M, Gorraiz M, Ruiz M, Belsue V, et al. Inhibition of FOXP3/NFAT Interaction Enhances T Cell Function after TCR Stimulation. J Immunol (2015) 195(7):3180-9. doi: 10.4049/ jimmunol.1402997

187. Lozano T, Gorraiz M, Lasarte-Cia A, Ruiz M, Rabal O, Oyarzabal J, et al. Blockage of FOXP3 transcription factor dimerization and FOXP3/AML1 interaction inhibits $\mathrm{T}$ regulatory cell activity: sequence optimization of a peptide inhibitor. Oncotarget (2017) 8(42):71709-24. doi: 10.18632/ oncotarget. 17845

188. Hay RT. SUMO: a history of modification. Mol Cell (2005) 18(1):1-12. doi: 10.1016/j.molcel.2005.03.012

189. Wang CM, Yang WH, Liu R, Wang L, Yang WH. FOXP3 Activates SUMOConjugating UBC9 Gene in MCF7 Breast Cancer Cells. Int J Mol Sci (2018) 19(7):2036. doi: 10.3390/ijms19072036

190. Ding X, Wang A, Ma X, Demarque M, Jin W, Xin H, et al. Protein SUMOylation Is Required for Regulatory T Cell Expansion and Function. Cell Rep (2016) 16(4):1055-66. doi: 10.1016/j.celrep.2016.06.056

191. Lu L, Barbi J, Pan F. The regulation of immune tolerance by FOXP3. Nat Rev Immunol (2017) 17(11):703-17. doi: 10.1038/nri.2017.75

192. Buckner JH. Mechanisms of impaired regulation by CD4(+)CD25(+)FOXP3 $(+)$ regulatory $\mathrm{T}$ cells in human autoimmune diseases. Nat Rev Immunol (2010) 10(12):849-59. doi: 10.1038/nri2889

193. Sarkar S, Fox DA. Regulatory T cell defects in rheumatoid arthritis. Arthritis Rheumatol (2007) 56(3):710-3. doi: 10.1002/art.22415

194. Romano M, Fanelli G, Albany CJ, Giganti G, Lombardi G. Past, Present, and Future of Regulatory T Cell Therapy in Transplantation and Autoimmunity. Front Immunol (2019) 10:43. doi: 10.3389/fimmu.2019.00043

195. Duffy MM, Uber L. Immunosuppressive medications. S C Nurse (1993) 8 (2):16-7.

196. Dantal J, Soulillou JP. Immunosuppressive drugs and the risk of cancer after organ transplantation. N Engl J Med (2005) 352(13):1371-3. doi: 10.1056/ NEJMe058018

197. Zhang Q, Lu W, Liang CL, Chen Y, Liu H, Qiu F, et al. Chimeric Antigen Receptor (CAR) Treg: A Promising Approach to Inducing Immunological Tolerance. Front Immunol (2018) 9:2359. doi: 10.3389/fimmu.2018.02359

198. Boroughs AC, Larson RC, Choi BD, Bouffard AA, Riley LS, Schiferle E, et al. Chimeric antigen receptor costimulation domains modulate human regulatory T cell function. JCI Insight (2019) 5:e126194. doi: 10.1172/ jci.insight.126194

199. Gonzalez-Galarza FF, Takeshita LY, Santos EJ, Kempson F, Maia MH, da Silva AL, et al. Allele frequency net 2015 update: new features for HLA epitopes, KIR and disease and HLA adverse drug reaction associations. Nucleic Acids Res (2015) 43(Database issue):D784-8. doi: 10.1093/nar/ gku1166

200. Burt C, Cryer C, Fuggle S, Little AM, Dyer P. HLA-A, -B, -DR allele group frequencies in 7007 kidney transplant list patients in 27 UK centres. Int $J$ Immunogenet (2013) 40(3):209-15. doi: 10.1111/iji.12000

201. MacDonald KG, Hoeppli RE, Huang Q, Gillies J, Luciani DS, Orban PC, et al. Alloantigen-specific regulatory $\mathrm{T}$ cells generated with a chimeric antigen receptor. J Clin Invest (2016) 126(4):1413-24. doi: 10.1172/JCI82771

202. Nishikawa H, Sakaguchi S. Regulatory T cells in cancer immunotherapy. Curr Opin Immunol (2014) 27:1-7. doi: 10.1016/j.coi.2013.12.005

203. Liu C, Workman CJ, Vignali DA. Targeting regulatory T cells in tumors. FEBS J (2016) 283(14):2731-48. doi: 10.1111/febs.13656

204. Esfahani K, Roudaia L, Buhlaiga N, Del Rincon SV, Papneja N, Miller WHJr. A review of cancer immunotherapy: from the past, to the present, to the future. Curr Oncol (2020) 27(Suppl 2):S87-97. doi: 10.3747/co.27.5223 
205. Buchbinder EI, Desai A. CTLA-4 and PD-1 Pathways: Similarities, Differences, and Implications of Their Inhibition. Am J Clin Oncol (2016) 39(1):98-106. doi: 10.1097/COC.0000000000000239

206. Walker LS. Treg and CTLA-4: two intertwining pathways to immune tolerance. J Autoimmun (2013) 45:49-57. doi: 10.1016/j.jaut.2013.06.006

207. Kamada T, Togashi Y, Tay C, Ha D, Sasaki A, Nakamura Y, et al. PD-1(+) regulatory T cells amplified by PD-1 blockade promote hyperprogression of cancer. Proc Natl Acad Sci USA (2019) 116(20):9999-10008. doi: 10.1073/ pnas. 1822001116

208. Tanaka A, Sakaguchi S. Regulatory T cells in cancer immunotherapy. Cell Res (2017) 27(1):109-18. doi: 10.1038/cr.2016.151

209. Yoshida K, Okamoto M, Sasaki J, Kuroda C, Ishida H, Ueda K, et al. AntiPD-1 antibody decreases tumour-infiltrating regulatory T cells. BMC Cancer (2020) 20(1):25. doi: 10.1186/s12885-019-6499-y

210. Cai J, Wang D, Zhang G, Guo X. The Role Of PD-1/PD-L1 Axis In Treg Development And Function: Implications For Cancer Immunotherapy. Onco Targets Ther (2019) 12:8437-45. doi: 10.2147/OTT.S221340

211. Takahashi T, Kuniyasu Y, Toda M, Sakaguchi N, Itoh M, Iwata M, et al. Immunologic self-tolerance maintained by $\mathrm{CD} 25+\mathrm{CD} 4+$ naturally anergic and suppressive T cells: induction of autoimmune disease by breaking their anergic/suppressive state. Int Immunol (1998) 10(12):1969-80. doi: 10.1093/ intimm/10.12.1969

212. Wing K, Onishi Y, Prieto-Martin P, Yamaguchi T, Miyara M, Fehervari Z, et al. CTLA-4 control over Foxp3+ regulatory T cell function. Science (2008) 322(5899):271-5. doi: 10.1126/science.1160062

213. Linsley PS, Bradshaw J, Greene J, Peach R, Bennett KL, Mittler RS. Intracellular trafficking of CTLA-4 and focal localization towards sites of TCR engagement. Immunity (1996) 4(6):535-43. doi: 10.1016/s1074-7613 (00)80480-x

214. Krummel MF, Allison JP. CTLA-4 engagement inhibits IL-2 accumulation and cell cycle progression upon activation of resting T cells. J Exp Med (1996) 183(6):2533-40. doi: 10.1084/jem.183.6.2533

215. Amarnath S, Mangus CW, Wang JC, Wei F, He A, Kapoor V, et al. The PDL1-PD1 axis converts human TH1 cells into regulatory T cells. Sci Transl Med (2011) 3(111):111ra20. doi: 10.1126/scitranslmed.3003130

216. Wherry EJ. T cell exhaustion. Nat Immunol (2011) 12(6):492-9. doi: 10.1038/ni.2035

217. Herbst RS, Soria JC, Kowanetz M, Fine GD, Hamid O, Gordon MS, et al. Predictive correlates of response to the anti-PD-L1 antibody MPDL3280A in cancer patients. Nature (2014) 515(7528):563-7. doi: 10.1038/nature14011

218. Liu Y, Wang L, Predina J, Han R, Beier UH, Wang LC, et al. Inhibition of p300 impairs Foxp3(+) T regulatory cell function and promotes antitumor immunity. Nat Med (2013) 19(9):1173-7. doi: 10.1038/nm.3286

219. Pettersson M, Crews CM. PROteolysis TArgeting Chimeras (PROTACs) Past, present and future. Drug Discovery Today Technol (2019) 31:15-27. doi: 10.1016/j.ddtec.2019.01.002

220. Dyck L, Mills KHG. Immune checkpoints and their inhibition in cancer and infectious diseases. Eur J Immunol (2017) 47(5):765-79. doi: 10.1002/ eji.201646875

221. Khadem F, Gao X, Mou Z, Jia P, Movassagh H, Onyilagha C, et al. Hepatic stellate cells regulate liver immunity to visceral leishmaniasis through P110delta-dependent induction and expansion of regulatory $\mathrm{T}$ cells in mice. Hepatology (2016) 63(2):620-32. doi: 10.1002/hep.28130

222. Yamada A, Arakaki R, Saito M, Tsunematsu T, Kudo Y, Ishimaru N. Role of regulatory $\mathrm{T}$ cell in the pathogenesis of inflammatory bowel disease. World $\mathrm{J}$ Gastroenterol (2016) 22(7):2195-205. doi: 10.3748/wjg.v22.i7.2195

223. Kimura A, Kishimoto T. IL-6: regulator of Treg/Th17 balance. Eur J Immunol (2010) 40(7):1830-5. doi: 10.1002/eji.201040391

224. Littman DR, Rudensky AY. Th17 and regulatory T cells in mediating and restraining inflammation. Cell (2010) 140(6):845-58. doi: 10.1016/ j.cell.2010.02.021
225. Di Giovangiulio M, Rizzo A, Franze E, Caprioli F, Facciotti F, Onali S, et al. Tbet Expression in Regulatory T Cells Is Required to Initiate Th1-Mediated Colitis. Front Immunol (2019) 10:2158. doi: 10.3389/fimmu.2019.02158

226. Wan YY, Flavell RA. 'Yin-Yang' functions of transforming growth factorbeta and $\mathrm{T}$ regulatory cells in immune regulation. Immunol Rev (2007) 220:199-213. doi: 10.1111/j.1600-065X.2007.00565.x

227. Giuffrida P, Cococcia S, Delliponti M, Lenti MV, Di Sabatino A. Controlling Gut Inflammation by Restoring Anti-Inflammatory Pathways in Inflammatory Bowel Disease. Cells (2019) 8(5):397. doi: 10.3390/cells8050397

228. Wang L, Beier UH, Akimova T, Dahiya S, Han R, Samanta A, et al. Histone/ protein deacetylase inhibitor therapy for enhancement of Foxp3+ Tregulatory cell function posttransplantation. Am J Transpl (2018) 18 (7):1596-603. doi: 10.1111/ajt.14749

229. HogenEsch H, Nikitin AY. Challenges in pre-clinical testing of anti-cancer drugs in cell culture and in animal models. J Control Release (2012) 164 (2):183-6. doi: 10.1016/j.jconrel.2012.02.031

230. Sariol CA, White LJ. Utility, limitations, and future of non-human primates for dengue research and vaccine development. Front Immunol (2014) 5:452. doi: 10.3389/fimmu.2014.00452

231. Carvalho C, Gaspar A, Knight A, Vicente L. Ethical and Scientific Pitfalls Concerning Laboratory Research with Non-Human Primates, and Possible Solutions. Anim (Basel) (2018) 9(1):12. doi: 10.3390/ani9010012

232. Simian M, Bissell MJ. Organoids: A historical perspective of thinking in three dimensions. J Cell Biol (2017) 216(1):31-40. doi: 10.1083/jcb.201610056

233. Bhatia SN, Ingber DE. Microfluidic organs-on-chips. Nat Biotechnol (2014) 32(8):760-72. doi: 10.1038/nbt.2989

234. Tanaka A, Sakaguchi S. Targeting Treg cells in cancer immunotherapy. Eur $J$ Immunol (2019) 49(8):1140-6. doi: 10.1002/eji.201847659

235. Oehme I, Linke JP, Bock BC, Milde T, Lodrini M, Hartenstein B, et al. Histone deacetylase 10 promotes autophagy-mediated cell survival. Proc Natl Acad Sci USA (2013) 110(28):E2592-601. doi: 10.1073/pnas.1300113110

236. Nakayama KI, Nakayama K. Ubiquitin ligases: cell-cycle control and cancer. Nat Rev Cancer (2006) 6(5):369-81. doi: 10.1038/nrc1881

237. Liu Q, Wang X, Liu X, Kumar S, Gochman G, Ji Y, et al. Use of Polymeric Nanoparticle Platform Targeting the Liver To Induce Treg-Mediated Antigen-Specific Immune Tolerance in a Pulmonary Allergen Sensitization Model. ACS Nano (2019) 13(4):4778-94. doi: 10.1021/acsnano.9b01444

238. LaMothe RA, Kolte PN, Vo T, Ferrari JD, Gelsinger TC, Wong J, et al. Tolerogenic Nanoparticles Induce Antigen-Specific Regulatory T Cells and Provide Therapeutic Efficacy and Transferrable Tolerance against Experimental Autoimmune Encephalomyelitis. Front Immunol (2018) 9:281. doi: 10.3389/fimmu.2018.00281

239. Prasad S, Neef T, Xu D, Podojil JR, Getts DR, Shea LD, et al. Tolerogenic Ag-PLG nanoparticles induce tregs to suppress activated diabetogenic CD4 and CD8 T cells. J Autoimmun (2018) 89:112-24. doi: 10.1016/ j.jaut.2017.12.010

240. Carambia A, Freund B, Schwinge D, Bruns OT, Salmen SC, Ittrich H, et al. Nanoparticle-based autoantigen delivery to Treg-inducing liver sinusoidal endothelial cells enables control of autoimmunity in mice. J Hepatol (2015) 62(6):1349-56. doi: 10.1016/j.jhep.2015.01.006

Conflict of Interest: The authors declare that the research was conducted in the absence of any commercial or financial relationships that could be construed as a potential conflict of interest.

Copyright $\odot 2021$ Dong, Yang and Pan. This is an open-access article distributed under the terms of the Creative Commons Attribution License (CC BY). The use, distribution or reproduction in other forums is permitted, provided the original author(s) and the copyright owner(s) are credited and that the original publication in this journal is cited, in accordance with accepted academic practice. No use, distribution or reproduction is permitted which does not comply with these terms. 